\title{
Biophysical, docking, and cellular studies on the effects of cerium oxide nanoparticles on blood components: in vitro
}

This article was published in the following Dove Press journal:

International Journal of Nanomedicine

\begin{abstract}
Neda Eskandari, ',* Mohammad Mahdi Nejadi Babadaei, ,*

Sanaz Nikpur, ${ }^{2}$ Ghazal

Ghasrahmad, ${ }^{2}$ Farnoosh Attar, ${ }^{3}$

Masoumeh Heshmati,' Keivan

Akhtari, ${ }^{4}$ Seyed Mahdi Rezayat

Sorkhabadi, ${ }^{5}$ Seyyedeh Elaheh

Mousavi, ${ }^{5}$ Mojtaba Falahati ${ }^{6}$

'Department of Cellular and Molecular Biology, Faculty of Advance Science and Technology, Pharmaceutical Sciences

Branch, Islamic Azad University (IAUPS),

Tehran, Iran; ${ }^{2}$ Department of Toxicology and Pharmacology, Faculty of Pharmacy,

Pharmaceutical Science Branch, Islamic Azad University (IAUPS), Tehran, Iran;

${ }^{3}$ Department of Biology, Faculty of Food Industry \& Agriculture, Standard Research Institute (SRI), Karaj, Iran; ${ }^{4}$ Department of Physics, University of Kurdistan, Sanandaj, Iran; ${ }^{5}$ Department of Pharmacology, School of Medicine, Tehran University of Medical

Sciences, Tehran, Iran; ${ }^{6}$ Department of Nanotechnology, Faculty of Advance Science and Technology, Pharmaceutical Sciences Branch, Islamic Azad University (IAUPS), Tehran, Iran
\end{abstract}

*These authors contributed equally to this work
Correspondence: Mojtaba Falahati Department of Nanotechnology, Faculty of Advance Science and Technology, Pharmaceutical Sciences Branch, Islamic Azad University (IAUPS), Tehran, Iran Email falahati@ibb.ut.ac.ir

Seyyedeh Elaheh Mousavi Department of Pharmacology, School of Medicine, Tehran University of Medical Sciences, PO Box 13145784, Tehran, Iran Emailsemousavi@sina.tums.ac.ir
Introduction: The application of nanoparticles (NPs) in medicine and biology has received great interest due to their novel features. However, their adverse effects on the biological system are not well understood.

Materials and methods: This study aims to evaluate the effect of cerium oxide nanoparticles (CNPs) on conformational changes of human hemoglobin $(\mathrm{HHb})$ and lymphocytes by different spectroscopic (intrinsic and synchronous fluorescence spectroscopy and far and near circular dichroism [CD] spectroscopy), docking and cellular (MTT and flow cytometry) investigations. Results and discussion: Transmission electron microscopy (TEM) showed that CNP diameter is $\sim 30 \mathrm{~nm}$. The infrared spectrum demonstrated a strong band around $783 \mathrm{~cm}^{-1}$ corresponding to the CNP stretching bond. Fluorescence data revealed that the CNP is able to quench the intrinsic fluorescence of $\mathrm{HHb}$ through both dynamic and static quenching mechanisms. The binding constant $\left(K_{b}\right)$, number of binding sites $(\mathrm{n})$, and thermodynamic parameters over three different temperatures indicated that hydrophobic interactions might play a considerable role in the interaction of CNPs with HHb. Synchronous fluorescence spectroscopy indicated that microenvironmental changes around Trp and Tyr residues remain almost unchanged. CD studies displayed that the regular secondary structure of $\mathrm{HHb}$ had no significant changes; however, the quaternary structure of protein is subjected to marginal structural changes. Docking studies showed the larger CNP cluster is more oriented toward experimental data, compared with smaller counterparts. Cellular assays revealed that CNP, at high concentrations $(>50 \mu \mathrm{g} / \mathrm{mL})$, initiated an antiproliferative response through apoptosis induction on lymphocytes.

Conclusion: The findings may exhibit that, although CNPs did not significantly perturb the native conformation of $\mathrm{HHb}$, they can stimulate some cellular adverse effects at high concentrations that may limit the medicinal and biological application of CNPs. In other words, CNP application in biological systems should be done at low concentrations.

Keywords: cerium oxide nanoparticles, human hemoglobin, fluorescence spectroscopy, thermodynamic, circular dichroism spectroscopy, docking, flow cytometry

\section{Introduction}

Research on the interactions of nanoparticles (NPs) with cells and biomolecules such as protein and DNA has potentially received a great interest in the field of biotechnology and biomedicine for decades. The nature and kind of interactions influence the biosafety, delivery mechanisms, drug design, and therapeutic efficacy. Therefore, studies on the interaction of nanomaterials with cells and biomolecules can open new avenues in understanding the structural characteristic required for the bio-affinity of NPs toward pharmacological activity. ${ }^{1-4}$ Nanomaterials can demonstrate a strong influence on cell 
viability and structural and corresponding functional features of biomolecules. Therefore, continuous interest has been focused toward comprehending the fundamental effects of NPs for interaction with biological systems..$^{5-7}$

Cerium oxide NPs (CNPs; nanoceria) have shown a number of biomedical features such as antiemetic, bacteriostatic, bactericidal, immunomodulatory, and antitumor activities. ${ }^{8}$ Moreover, CNPs have been shown to improve mild traumatic brain injury in vitro and in vivo and provide neuroprotective potential for focal cerebral ischemic stroke. ${ }^{9,10}$ Furthermore, CNPs have stimulated the proliferation of primary mouse embryonic fibroblasts in vitro. ${ }^{11}$

Recently, CNPs have been shown to have a potential application in the development of catalytic antioxidants in biology and medicine. ${ }^{12,13}$ CNPs have commonly showed antioxidant activity as biomimetic enzymes and have demonstrated a capacity to actively scavenge a variety of free radicals in vitro and in vivo. ${ }^{12-16}$

Blood components are known to be one of the first biological systems that interact with nanomaterials, which generates great interest to explore the reaction of different blood components against NPs.

Human hemoglobin $(\mathrm{HHb})$ has a quaternary structure with four subunits. ${ }^{17}$ Each subunit is composed of a protein chain with a dominant $\alpha$-helical structure tightly associated with a non-protein prosthetic heme group. ${ }^{17} \mathrm{HHb}$ is known as a two-way respiratory transport protein, carrying oxygen and carbon dioxide between the lungs and tissues. ${ }^{18}$ In addition, $\mathrm{HHb}$ plays an exceptional role in not only a buffering action ${ }^{18}$ for oxygen, but also acts as a potential agent in the transport of a number of drugs to their targeted tissues. ${ }^{19,20}$

To further investigate the side effects of CNPs in the bloodstream, lymphocyte cell viability was explored to examine the effects of CNPs on the basic immunological functions of human lymphocytes.

Optical techniques such as near and far circular dichroism (CD) and fluorescence spectroscopy were employed as practical tools due to their great sensitivity, speed, and simplicity for studying ligand-protein interactions. ${ }^{21-24}$ A docking study was employed to verify experimental data.

Furthermore, MTT assay and flow cytometry was carried out to explore the antiproliferative effect of CNPs on lymphocytes.

\section{Materials and methods Materials}

The $\mathrm{HHb}$ was obtained from Sigma-Aldrich Company (Sigma-Aldrich, St Louis, MO, USA). The concentration was determined spectrophotometrically on the basis of the Bradford assay. CNPs (99.97\%, $30 \mathrm{~nm})$ were purchased from US-Nano Company (USA). All other materials were of analytical grade.

\section{Methods}

\section{Preparation of $\mathrm{Hb}$ and NPs}

Defined concentrations of $\mathrm{HHb}$ and CNPs were prepared

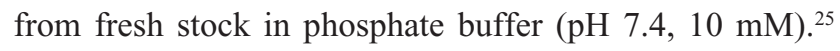
In order to increase the colloidal stability of CNP, the stock suspension was mixed by vortex for $5 \mathrm{~min}$, and sonicated for $30 \mathrm{~min}$ using a sonicator probe (Misonix-S3000, USA) at room temperature.

\section{TEM analysis}

Image of CNPs were recorded with a TEM (Zeiss, EM10C, Germany) operated at $100 \mathrm{kV}$. Samples was prepared by sonication for $30 \mathrm{~min}$ using a Misonix sonicator (S3000) and by depositing a few droplets of dilute CNP solution on to a carbon film. The CNP diameter was analyzed to reveal the morphology and diameter of the individual CNP.

\section{Infrared spectroscopy}

The Fourier transform infrared (FTIR) spectrum of the CNP was recorded in the transmission mode at room temperature using the potassium bromide $(\mathrm{KBr})$ pellet technique. The $\mathrm{KBr}$ was dried in a dryer at $200^{\circ} \mathrm{C}$ for $24 \mathrm{~h} .20 \mathrm{mg} \mathrm{KBr}$ was then homogenized with CNPs and, thereafter, ground to fine powder. A Perkin-Elmer FTIR (Model 2000) spectrophotometer was employed to determine the spectrum of CNPs mixed with spectrally pure $\mathrm{KBr}$ and then pressed to form thin plates of $0.1 \mathrm{~cm}^{-1}$ thickness. The sample was then subjected to FTIR spectroscopic analysis in the wavelength range of $400-4,000 \mathrm{~cm}^{-1}$.

\section{Measurement of fluorescence during the reaction of CNPs with $\mathrm{HHb}$}

Fluorescence measurements were performed using a Hitachi spectrofluorometer (MPF-4 model, Japan). HHb $(2.5 \mu \mathrm{M})$ was incubated with different concentrations of CNPs (2.5-27.5 $\mu \mathrm{M})$ in $10 \mathrm{mM}$ potassium phosphate buffer, at $\mathrm{pH} 7.4$, in a total volume of $0.5 \mathrm{~mL}$ at different temperatures of 298,310 , and $315 \mathrm{~K}$ for $2 \mathrm{~min}$. With an excitation wavelength of $280 \mathrm{~nm}$, two emission wavelengths at 340 and $380 \mathrm{~nm}$ for $\mathrm{HHb}$ and $\mathrm{CNP}$, respectively, were detected. The slit widths of excitation and emission were set at 5 and $10 \mathrm{~nm}$, respectively. All measurements were corrected against buffer solution and inner filter effect. 


\section{Synchronous fluorescence spectra}

The synchronous fluorescence spectra of protein $(2.5 \mu \mathrm{M})$ in the presence of CNPs $(2.5-27.5 \mu \mathrm{M})$ were scanned from 260 to $310 \mathrm{~nm}$ with an excitation wavelength of $\Delta \lambda=20$ (detecting microenvironmental changes of $T y r$ residue) and $\Delta \lambda=60 \mathrm{~nm}$ (detecting microenvironmental changes of $\operatorname{Tr} p$ residue). All measurements were undertaken at room temperature and, finally, were subtracted from the buffer solution and inner filter effect.

\section{CD measurements}

CD spectra were recorded using an Aviv model 215 spectropolarimeter (Lakewood, NJ, USA) at room temperature. Changes in the secondary and quaternary structures of $\mathrm{HHb}$ in the absence and presence of different concentrations of CNPs were monitored in the far UV-CD region (200-250 nm) and near UV-CD region (260-350 nm), respectively. The protein concentration for far and near $\mathrm{CD}$ was 3 and $15 \mu \mathrm{M}$, respectively. The concentrations of CNPs for far $\mathrm{CD}$ were 3,10 , and $30 \mu \mathrm{M}$, whereas the concentrations of CNPs for near $\mathrm{CD}$ were 15,30 , and $45 \mu \mathrm{M}$. The results are expressed in molar ellipticity $[\theta]\left(\mathrm{cm}^{2} \mathrm{dmol}^{-1}\right)$ with a mean amino acid residue weight of 114 (MRW) for HHb. All CD bands were corrected against buffer and NP solutions.

\section{Molecular docking}

To model the CNPs, we used a $\mathrm{Ce}_{44} \mathrm{O}_{88}$ cluster as the model of larger particles and a $\mathrm{Ce}_{19} \mathrm{O}_{32}$ cluster as the model of smaller particles. Cartesian coordinates of atoms were directly obtained from supplementary files of Loschen et al's work, ${ }^{25}$ and these coordinates were converted to pdb files. The molecular docking study was carried out with HEX 6.3 software. ${ }^{26}$

\section{MTT assay}

Normal human peripheral lymphocytes from blood samples were isolated following gradient centrifugation on FicollPaque PLUS as described previously. ${ }^{27}$

Lymphocytes $\left(1 \times 10^{4}\right.$ cells/well) were cultured in complete RPMI-1640 media and incubated with different concentrations of CNPs $(1,10,50,100$, and $200 \mu \mathrm{g} / \mathrm{mL})$ for $48 \mathrm{~h}$ to explore their antiproliferative effect by using MTT assay. ${ }^{27}$

\section{Flow cytometry analysis}

Flow cytometric assay of control and CNP $(200 \mu \mathrm{g} / \mathrm{mL})$ incubated cells was carried out to quantify the percentage of the apoptotic cells. Cells were stained with fluorescein isothiocyanate (FITC)-Annexin V and propidium iodide (PI) by the flow cytometry kit according to the manufacturer's instruction (Abcam-Germany). Lymphocytes were incubated with $200 \mu \mathrm{g} / \mathrm{mL} \mathrm{CNPs}$ for $48 \mathrm{~h}$ at $37^{\circ} \mathrm{C}$ and $5 \% \mathrm{CO}_{2}$. Afterwards, the cells were collected, washed, resuspended in Annexin-binding buffer, and stained with Annexin V-FITC and PI in the dark. Finally, cells were immediately analyzed using a BD FACSCalibur flow cytometer (BD Biosciences, San Jose, CA, USA).

\section{Statistical analysis}

Statistical analysis was undertaken by Student's $t$-test. Data were reported as mean \pm standard errors (SEs). $P$-values of $<0.05$ were reported as significant.

\section{Results and discussion Characterizations of NPs}

The morphology of the CNP was characterized by the TEM image (Figure 1). From the TEM image result, it can be observed that a large quantity of uniformed NPs had an average particle size of $\sim 30 \mathrm{~nm}$.

Figure 2 shows the FTIR spectrum of CNP. It shows three strong bands around 3,449, 1,635, and $783 \mathrm{~cm}^{-1}$. The observed bands are similar to those already reported in Masui et al study. ${ }^{28}$ The vibration bands are at 738 (Ce-O stretching) and $1,635 \mathrm{~cm}^{-1}\left(\mathrm{H}_{2} \mathrm{O}\right.$ bending vibration), with a broad peak at $3,478 \mathrm{~cm}^{-1}\left(\mathrm{H}_{2} \mathrm{O}\right.$ stretching $)$.

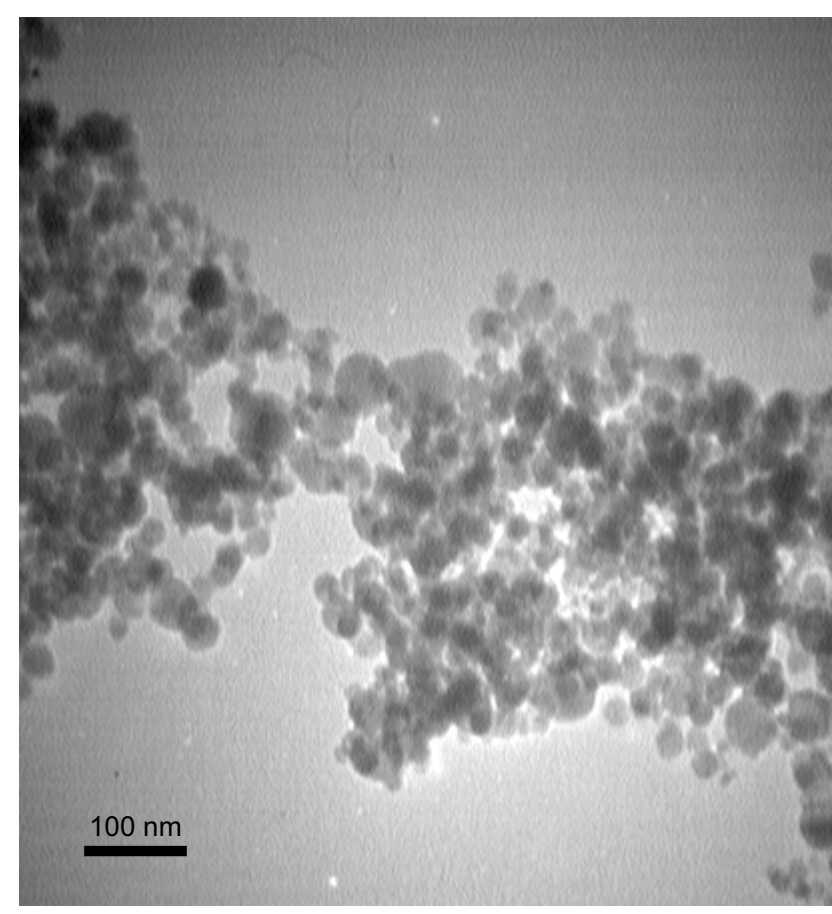

Figure I Transmission electron microscopy images of the CNP. 


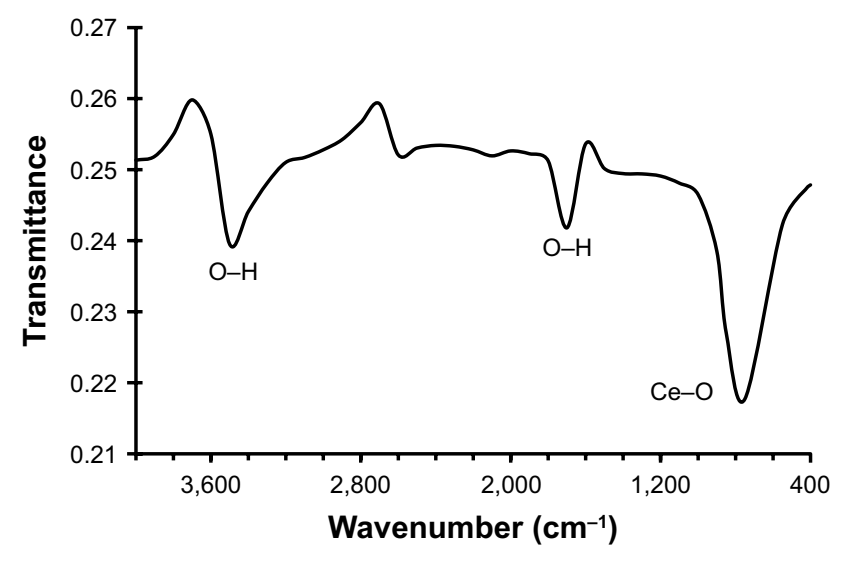

Figure 2 The FTIR spectrum of CNP. Three strong bands around 3,449, I,635, and $783 \mathrm{~cm}^{-1}$ are observed.

\section{Fluorescence studies}

Fluorescence spectroscopy is considered as a promising technique for studying the different aspects of protein-NP interactions. Intrinsic fluorescence intensity of the $\mathrm{HHb}$ originated from aromatic residues such as Trp, Tyr and Phe residues. Fluorescence quenching occurs through different possibilities such as static or dynamic mechanisms. Static quenching is defined as the complex formation between the ligand and the protein in the ground state. On the other hand, dynamic quenching occurs when a transient complex between the ligand and protein forms in the excited state. Dynamic or static quenching shows different reactions against temperature and viscosity. ${ }^{29}$

The Stern-Volmer equation has been widely used for the determination of quenching mechanism of proteins in the presence of ligands. ${ }^{30}$

$$
\frac{F_{o}}{F}=1+K_{S V}[\mathrm{CNP}]
$$

where $F_{o}$ and $F$ are fluorescence intensities in the absence and presence of the different concentrations of NPs (CNPs), respectively. The $K_{S V}$ presents the Stern-Volmer constant. Figure 3 showed that, as the concentration of CNPs increases, the fluorescence intensities of the protein decrease at $298 \mathrm{~K}$ (A), $310 \mathrm{~K}$ (B), and $315 \mathrm{~K}$ (C). Figure 3 revealed that after excitation of the HHb-CNP complex, two emissions bands at 340 and $384 \mathrm{~nm}$ were observed
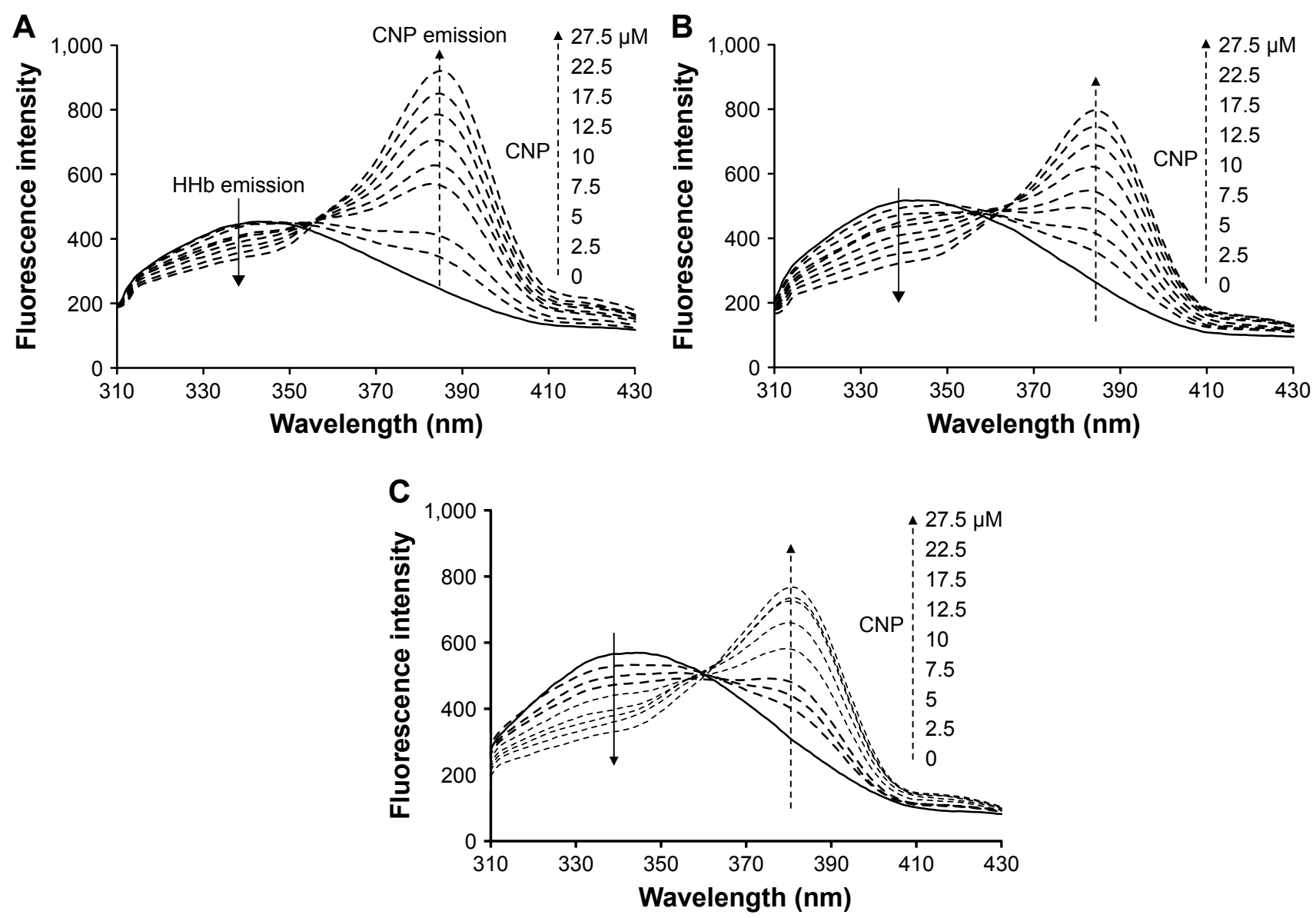

Figure 3 Fluorescence titration curve of $\mathrm{HHb}(2.5 \mu \mathrm{M})$ with the various concentrations of $\mathrm{CNPs}(0,2.5,5,7.5,10,12.5,17.5,22.5$, and $27.5 \mu \mathrm{M})$ in phosphate buffer at $\mathrm{pH} 7.4$ and $10 \mathrm{mM}$ at $289 \mathrm{~K}(\mathbf{A}), 310(\mathbf{B})$, and $315 \mathrm{~K}(\mathbf{C})$. 
corresponding to emission wavelengths of $\mathrm{HHb}$ and $\mathrm{CNP}$, respectively.

The $K_{S V}$ values for the $\mathrm{HHb}-\mathrm{CNP}$ complex at 298, 310, and $315 \mathrm{~K}$ were $11.4 \pm 1.9 \times 10^{3} \mathrm{M}^{-1}, 21.2 \pm 3.2 \times 10^{3} \mathrm{M}^{-1}$ and $24.4 \pm 3.8 \times 10^{3} \mathrm{M}^{-1}$, respectively (Figure 4, Table 1). The direct relation between temperature and $K_{S V}$ indicates the presence of a dynamic quenching mechanism between $\mathrm{HHb}$ and CNP. Moreover, dynamic and static quenching can be determined on the basis of the maximum collision-quenching rate constant $\left(k_{q}\right)$ of different NPs with the macromolecules, which is $2.0 \times 10^{10} \mathrm{M}^{-1} \mathrm{~s}^{-1} \cdot{ }^{21,24}$

Based on the following equation:

$$
\frac{F_{o}}{F}=1+k_{q} \tau_{o}[\mathrm{Q}]
$$

where, $\tau_{o}\left(10^{-9} \mathrm{~s}\right)$ is the average fluorescent life time of the macromolecules in the absence of quencher [Q], dynamic and static quenching can be distinguished. ${ }^{21,24}$ As summarized in Table $1, k_{q}$ values for CNP-HHb interaction are greater than $10^{10} \mathrm{M}^{-1} \mathrm{~s}^{-1}$. Therefore, it can be concluded that the quenching mechanism is probably caused by both static and dynamic quenching systems. Therefore, the binding parameters between CNPs and protein can be calculated.

\section{Binding parameters}

The binding parameters for the interaction of $\mathrm{CNP}$ with $\mathrm{HHb}$ were calculated on the basis of the fluorescence quenching data by using the following equation (3): ${ }^{31}$

$$
\log [\Delta F / F]=n \log [Q]+\log K_{b}
$$

where $\mathrm{n}$ is the number of binding sites of protein per NP and $K_{b}$ exhibits the equilibrium binding constant. The values of $\mathrm{n}$ and $K_{b}$ were estimated from the slope and y-intercept

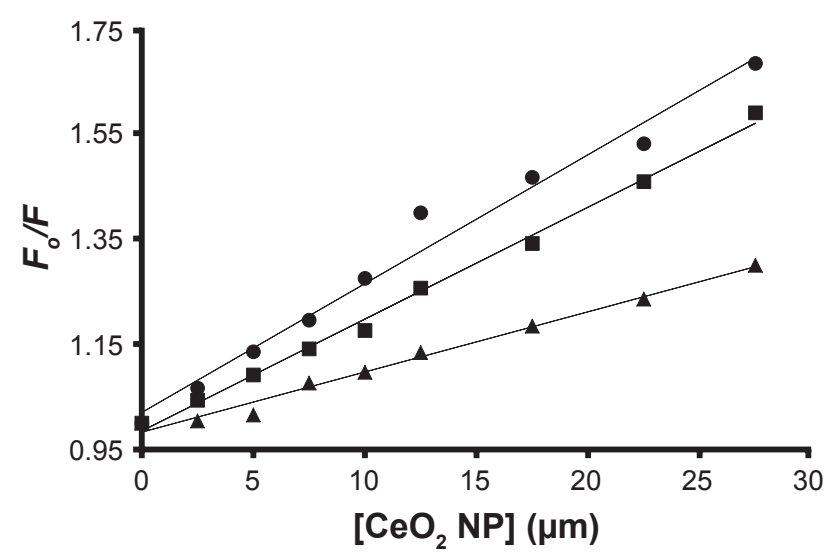

Figure 4 Stern-Volmer plots for the interaction of CNPs and $\mathrm{HHb}$ in phosphate buffer at $\mathrm{pH} 7.4$ and $10 \mathrm{mM}$ at $298(\mathbf{\Delta}), 310(\boldsymbol{\square})$, and $315 \mathrm{~K}(\bullet)$.
Table I $K_{s v}$ and $k_{q}$ values of the fluorescence quenching of $\mathrm{HHb}$ $(2.5 \mu \mathrm{M})$ in the presence of various concentrations of CNPs $(0,2.5,5,7.5,10,12.5,17.5,22.5$, and $27.5 \mu \mathrm{M})$ at three different temperatures

\begin{tabular}{lll}
\hline $\mathbf{T}(\mathbf{K})$ & $K_{s v}\left(\mathbf{M}^{-1}\right)$ & $\boldsymbol{k}_{q}\left(\mathbf{M}^{-1} \mathbf{s}^{-1}\right)$ \\
\hline 298 & $11.4 \pm 1.9 \times 10^{3}$ & $11.4 \pm 1.9 \times 10^{12}$ \\
310 & $21.2 \pm 3.2 \times 10^{3}$ & $21.2 \pm 3.2 \times 10^{12}$ \\
315 & $24.4 \pm 3.8 \times 10^{3}$ & $24.4 \pm 3.8 \times 10^{12}$ \\
\hline
\end{tabular}

Note: All data are expressed as mean \pm SE.

of $\log (\Delta F) / F$ versus $\log$ [Q], respectively. The $\log K_{b}$ was $4.2 \pm 0.7,5.6 \pm 0.9$, and $7.7 \pm 1.2 \mathrm{M}^{-1}$ at 298,310 , and $315 \mathrm{~K}$, respectively (Table 2 ).

Furthermore, it was reported that $\mathrm{n}$ increases from $0.97 \pm 0.1$ to $1.78 \pm 0.1$ as the temperature increases from 298 to $315 \mathrm{~K}$. Increasing temperature accelerates the protein unfolding characterized by an exposed hydrophobic core and some loss of quaternary structure. After it passed through the interaction state, the hydrophobic protein core rapidly became more disrupted and the binding-site loop was highly exposed. At higher temperatures, the protein reached a partially denatured state wherein there was virtually some unfolded structure, although fluctuating secondary and native quaternary structures existed. At lower temperatures, a sliding motion of the helix structure did not disrupt the hydrophobic patches of protein, and the interaction binding was weaker at lower temperatures as compared to higher temperatures. To prove that the hydrophobic interaction may play an important role in the interaction between $\mathrm{CNPs}$ and $\mathrm{HHb}$, thermodynamic parameters was calculated. Based on the sign of standard enthalpy change $\left(\Delta H^{\circ}\right)$ and standard entropy change $\left(\Delta S^{\circ}\right)$, the kind of interaction can be determined. ${ }^{32}$

\section{Thermodynamic parameters}

Considering the fact that the enthalpy change $\left(\Delta H^{\circ}\right)$ remains almost unchanged over the temperature range, $\Delta H^{\circ}$ and $\Delta S^{\circ}$ can be calculated using the van't Hoff Equation (4). ${ }^{33}$

$$
\ln K_{b}=\frac{-\Delta H^{\circ}}{\mathrm{RT}}+\frac{\Delta S^{\circ}}{\mathrm{R}}
$$

Table 2 The number of binding sites of protein (n) per NP and $K_{b}$ of $\mathrm{HHb}$ upon interaction with CNPs at three different temperatures of 298,310 , and $315 \mathrm{~K}$

\begin{tabular}{lll}
\hline $\mathbf{T}(\mathbf{K})$ & $\log K_{b}\left(\mathbf{M}^{-1}\right)$ & $n$ \\
\hline 298 & $4.2 \pm 0.7$ & $0.97 \pm 0.1$ \\
310 & $5.6 \pm 0.9$ & $1.08 \pm 0.1$ \\
315 & $7.7 \pm 1.2$ & $1.78 \pm 0.2$ \\
\hline
\end{tabular}

Note: All data are expressed as mean \pm SE. 


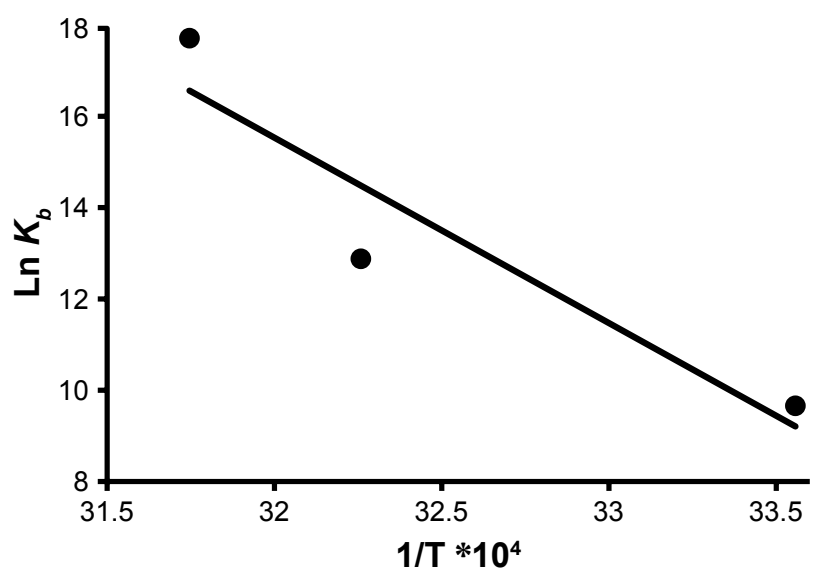

Figure 5 The plot of $L n K_{b}$ vs I/T (van't Hoff Plot).

$\Delta H^{\circ}$ and $\Delta S^{\circ}$ were estimated from the slope and the y-intercept of the plot of $\ln K_{b}$ vs $1 / T$, respectively (Figure 5).

Standard free Gibbs energy $\left(\Delta G^{\circ}\right)$ was then calculated from the Gibbs-Helmholtz Equation (5) $)^{34}$

$$
\Delta G^{\circ}=\Delta H^{\circ}-T \Delta S^{\circ}=-\mathrm{R} T \ln K_{b}
$$

The estimated data are summarized in Table 3 . The negative sign for $\Delta G^{\circ}$ indicated that the binding process between $\mathrm{HHb}$ and CNPs was spontaneous. Positive values of $\Delta H^{\circ}$ and $\Delta S^{\circ}$ revealed that hydrophobic forces are involved as the main interaction bonds between CNPs and HHb. ${ }^{35}$

To further support the premise that hydrophobic interaction may play an important role in the formation of the $\mathrm{CNP}-\mathrm{HHb}$ complex, a fluorescence quenching study was conducted. For this experiment, a fixed concentration of CNPs $(5 \mu \mathrm{M})$ was used and different concentrations of $\mathrm{HHb}$ (2-20 $\mu \mathrm{M})$ were added to the CNP solution. The excitation wavelength was set to $320 \mathrm{~nm}$. CNPs show strong adsorption intensity at $320 \mathrm{~nm}$ (data not shown). As shown in Figure 6, after the addition of $\mathrm{HHb}$, a quenching of CNP fluorescence intensity was observed. Moreover, a remarkable blue shift ( $4 \mathrm{~nm}$ ) was detected as the concentration of $\mathrm{HHb}$ increased. This significant blue shift indicates that CNPs have experienced a hydrophobic environment in the presence of $\mathrm{HHb}$,

Table 3 Thermodynamic parameters of $\mathrm{HHb}$ upon interaction with CNP at three different temperatures of 298,310 , and $315 \mathrm{~K}$

\begin{tabular}{llll}
\hline $\mathbf{T}(\mathrm{K})$ & $\Delta H^{\circ}(\mathrm{KJ} / \mathrm{mol})$ & $\mathbf{T} \Delta S^{\circ}(\mathrm{KJ} / \mathrm{mol})$ & $\Delta G^{\circ}(\mathrm{KJ} / \mathrm{mol})$ \\
\hline 298 & $146.5 \pm 24.7$ & $122.7 \pm 2 \mathrm{I} . \mathrm{I}$ & $-23.8 \pm 4.2$ \\
310 & $146.5 \pm 24.7$ & $1 \mathrm{I} 3.4 \pm 19.3$ & $-33.1 \pm 5.9$ \\
315 & $146.5 \pm 24.7$ & $100.2 \pm 15.6$ & $-46.3 \pm 8.2$ \\
\hline
\end{tabular}

Note: All data are expressed as mean \pm SE.

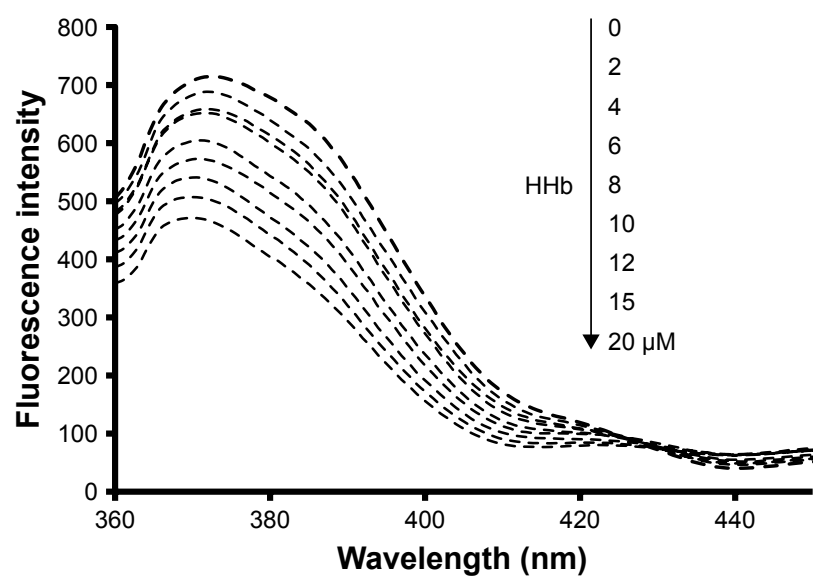

Figure 6 Fluorescence titration curve of CNPs $(5 \mu \mathrm{M})$ with the various concentrations of $\mathrm{HHb}(0,2,4,6,8,10,12,15$, and $20 \mu \mathrm{M})$ in phosphate buffer at $\mathrm{pH} 7.4$ and $10 \mathrm{mM}$ at $289 \mathrm{~K}$.

and hydrophobic interaction may play a considerable role in the interaction of CNPs with $\mathrm{HHb}$.

\section{Synchronous fluorescence spectroscopy}

Synchronous fluorescence spectroscopy is a useful technique in many biological systems to reveal the microenvironmental changes around aromatic residues. Synchronous fluorescence spectroscopy depends on a multitude of factors such as distance between the donor and acceptor and polarity around residues. ${ }^{35,36}$ Synchronous fluorescence spectroscopy demonstrates the microenvironmental alterations of Tyr and Trp residues when the $\Delta \lambda(\lambda \mathrm{em}-\lambda \mathrm{ex})$ is 20 and 60 $\mathrm{nm}$, respectively. The effect of CNPs on the synchronous fluorescence spectra of $\mathrm{HHb}$ is depicted in Figure 7A and B. It is indicated that, as the concentration of CNPs increases, the fluorescence intensity of $\mathrm{HHb}$ for both $\Delta \lambda=20$ and 60 $\mathrm{nm}$ decreases. However, no remarkable shift in the emission spectrum of $\mathrm{HHb}$ was detected. These data suggest that polarity and hydrophobicity around the Trp and Tyr residues remain constant. Briefly, the synchronous fluorescence spectra indicated that the conformation of $\mathrm{HHb}$ has not been markedly altered around $T y r$ and $T r p$ residues.

\section{CD studies}

The secondary and quaternary structural changes of $\mathrm{HHb}$ upon interaction with CNPs were investigated by far and near UV-CD, respectively.

Figure 8 shows the far UV-CD spectra $(200-250 \mathrm{~nm})$ of $\mathrm{HHb}$ in the absence and presence of different concentrations of CNPs at room temperature. The CD spectrum of $\mathrm{HHb}$ shows two characteristic minima at 208 and 
A

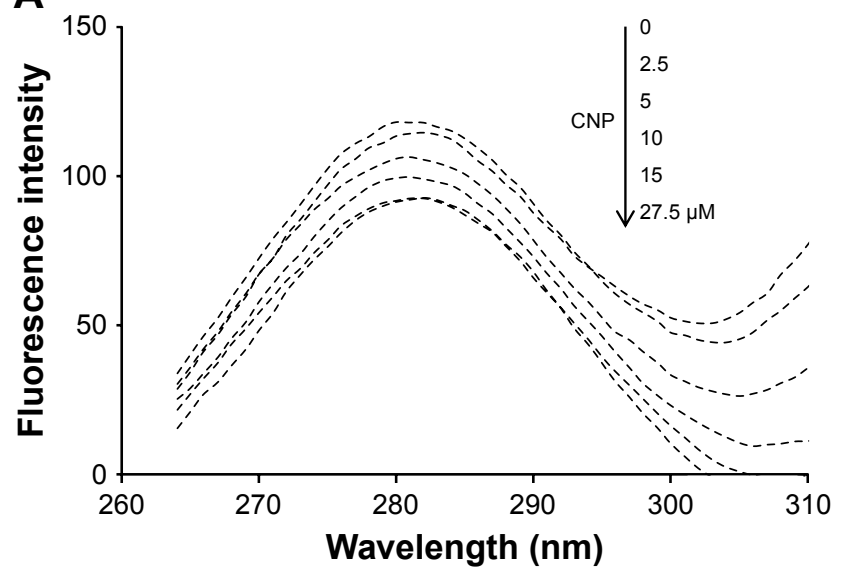

B

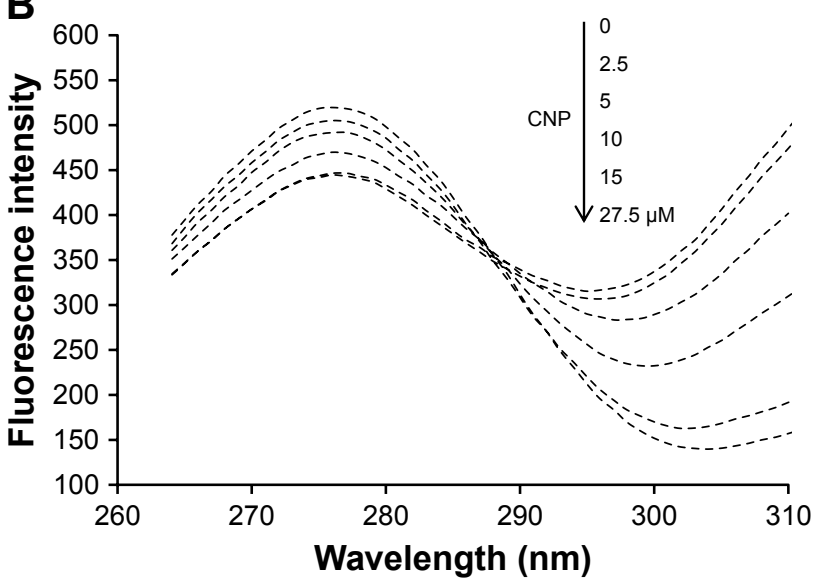

Figure 7 The effect of various concentrations of $\operatorname{CNPs}(0,2.5,5,10,15$, and $27.5 \mu \mathrm{M})$ on the synchronous fluorescence spectrum of $\mathrm{HHb}$ with $\Delta \lambda=20 \mathrm{~nm}(\mathbf{A})$ and $\Delta \lambda=60 \mathrm{~nm}(\mathbf{B})$.

$222 \mathrm{~nm}$, reflecting the $\alpha$-helical structure of the HHb. ${ }^{37-39}$ Figure 8 shows that the secondary structure of $\mathrm{HHb}$ has not experienced substantial structural changes after the addition of different concentrations of CNP. This data indicated that the regular secondary structure of the $\mathrm{HHb}$ remained unchanged after interaction with CNP. In other words, it may be proposed that the interaction of CNPs and $\mathrm{HHb}$ has not led to the NP-induced secondary structural changes of $\mathrm{HHb}$, and the native secondary structure of $\mathrm{HHb}$ is preserved.

Furthermore, near UV-CD (260-350) was employed to reveal the quaternary structural changes of $\mathrm{HHb}$ after interaction with CNP. The position of aromatic residues inside the protein can play considerable roles in the intensity of near UV-CD bands. Figure 9 shows that the band intensities at $285 \mathrm{~nm}(\operatorname{Trp}$ and $T y r)$ provide a negligible red shift (285-288 nm) after the addition of CNPs.

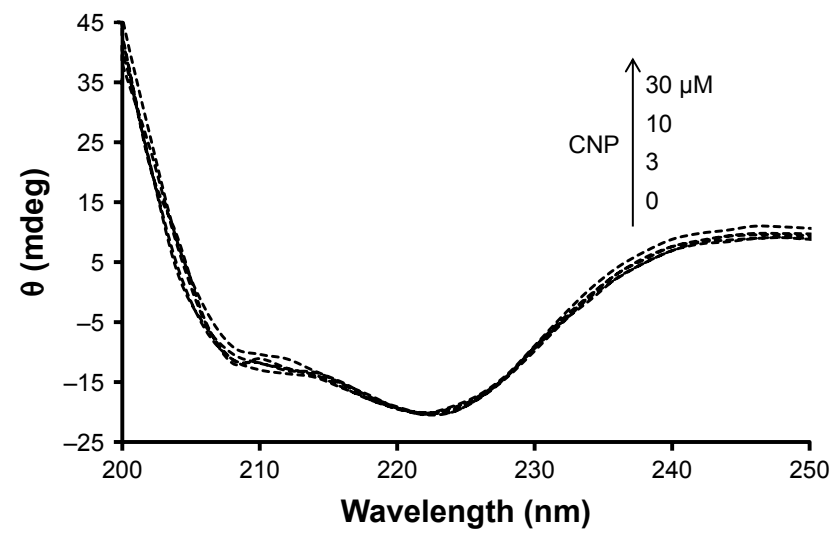

Figure 8 Far UV-CD spectra $(200-250 \mathrm{~nm})$ of $\mathrm{HHb}(3 \mu \mathrm{M})$ were measured in the absence and presence of different CNP concentrations of 3,10 , and $30 \mu \mathrm{M}$ in phosphate buffer at $\mathrm{pH} 7.4$ and $10 \mathrm{mM}$ at temperature $25^{\circ} \mathrm{C}$.
Synchronous fluorescence spectroscopy also showed that the polarity around $\operatorname{Tr} p$ and $T y r$ was not significantly altered.

As shown in Figure 9, the quaternary structure of $\mathrm{HHb}$ is marginally changed after the addition of CNPs. In other words, Phe, Trp, and Tyr residues have been subjected to a minor displacement inside the protein structure. Therefore, it can be concluded that a large number of Trp, Tyr, and Phe residues in the $\mathrm{HHb}$ experience negligible polarity changes. Moreover, it can be deduced that aromatic residues placed close to the surface moved to the polar environment, and this microenvironmental change cannot be detected by $\mathrm{CD}$ and fluorescence spectroscopic methods. The displacement of the helix structure of protein and a corresponding movement of aromatic residues to the different polar environment increases the overlap between positive and negative $\mathrm{CD}$ bands and finally results in reduced intensity of CD bands.

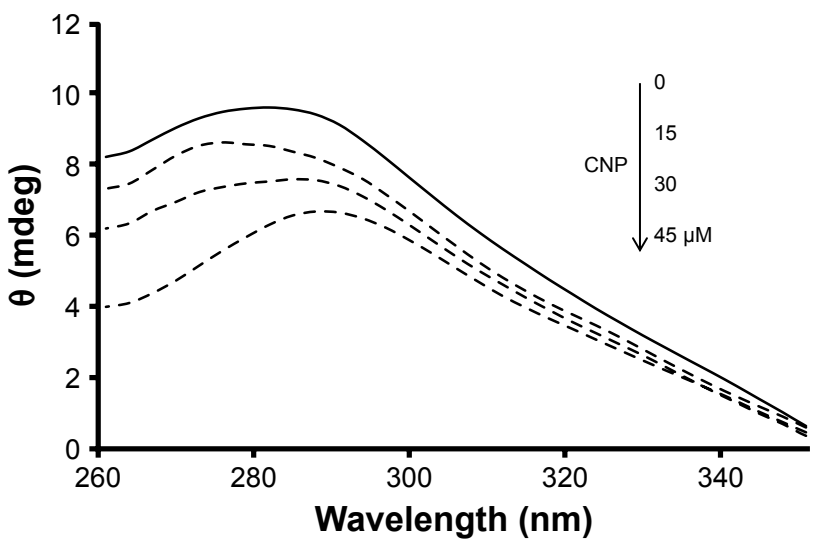

Figure 9 Near UV-CD spectra $(260-350 \mathrm{~nm})$ of $\mathrm{HHb}(15 \mu \mathrm{M})$ were measured in the absence and presence of different concentrations of CNPs I5, 30, and $45 \mu \mathrm{M}$ in phosphate buffer at $\mathrm{pH} 7.4$ and $10 \mathrm{mM}$ at temperature $25^{\circ} \mathrm{C}$. 
$\mathrm{HHb}$ has 30 Phe $\left(33,36,43,46,98,117,128,182,183, \quad\right.$ Phe residues 182 ( $\beta_{1}$ subunit) and 469 ( $\beta_{2}$ subunit), Trp 186, 212, 226, 244, 259, 263, 320, 323, 330, 333, 385, 404, 415, 469, 470, 473, 499, 513, 531, 546, and 550), six $\operatorname{Trp}(14$, $156,178,301,443$, and 465$)$, and $12 \mathrm{Tyr}$ residues $(24,42,140$, 176, 271, 286, 311, 329, 427, 463, 558, and 573; Figure 10).

The near UV-CD experiment indicated that the hydrophobicity and polar environment around aromatic residues has not been significantly altered. It may be proposed that residues 14 ( $\alpha_{1}$ subunit), 156 ( $\beta_{1}$ subunit), 301 ( $\alpha_{2}$ subunit), and 465 ( $\beta_{2}$ subunit), and Tyr residues 286 ( $\beta_{1}$ subunit), 463 ( $\beta_{2}$ subunit), and 573 ( $\beta_{2}$ subunit) are more accessible to the solvent and are mainly involved in the interaction of CNPs with $\mathrm{HHb}$ (Figure 10).

To elucidate the accessible sites of $\mathrm{HHb}$ for NP interaction, a docking study was conducted.

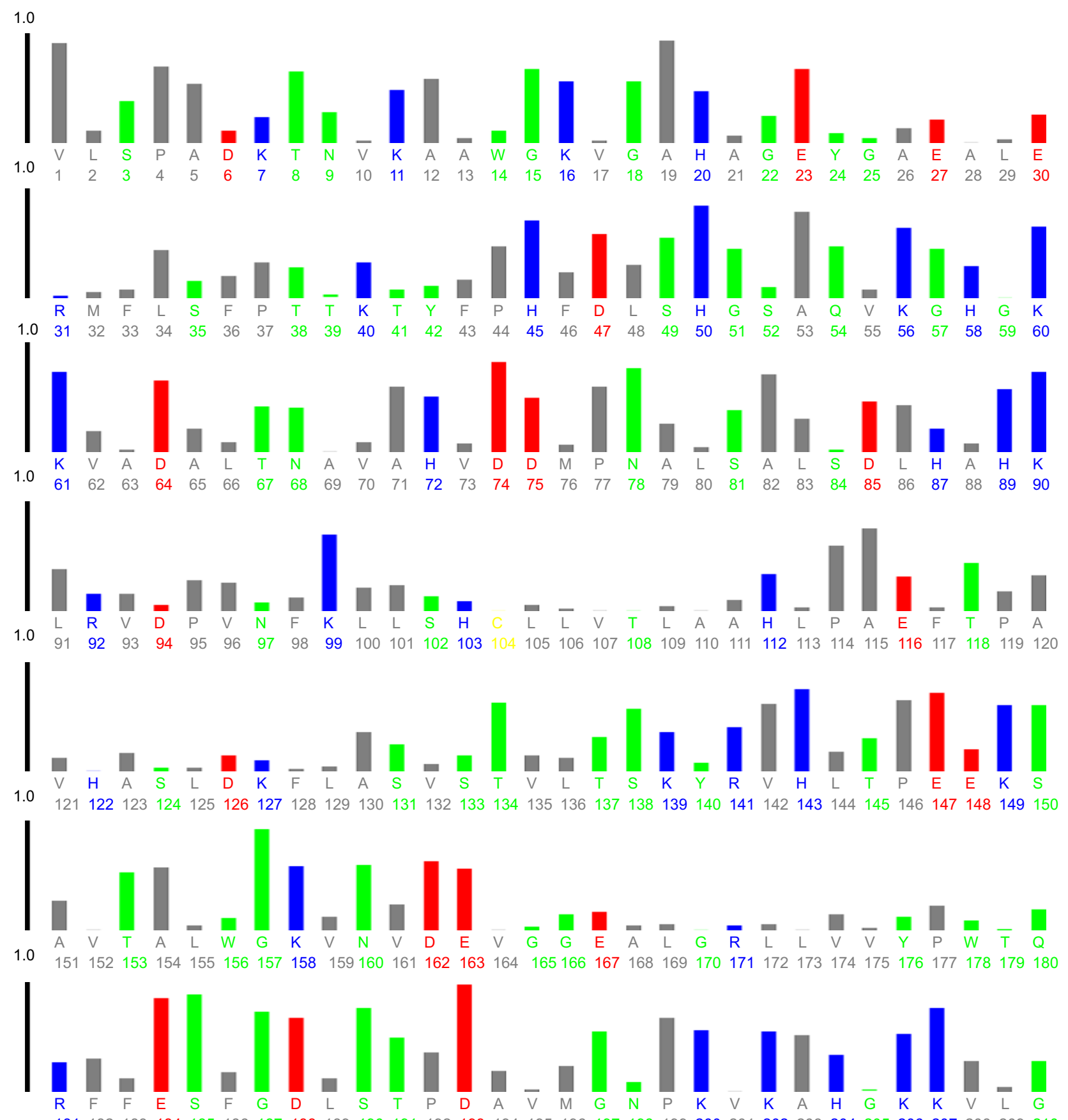
181182183184185186187188189190191192193194195196197198199200201202203204205206207208209210

Figure 10 (Continued) 

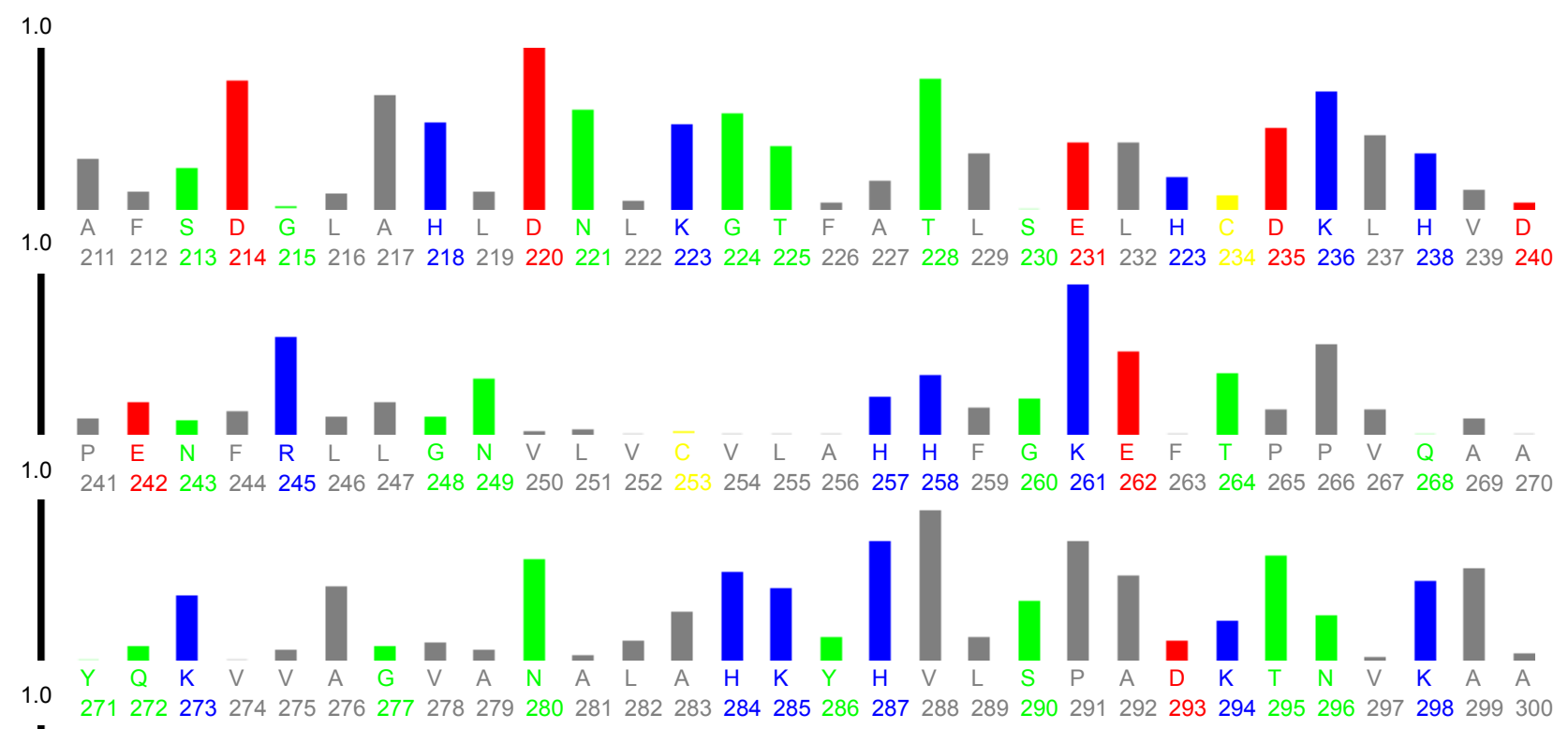

1.0271272273274275276277278279280281282283284285286287288289290291292293294295296297298299300
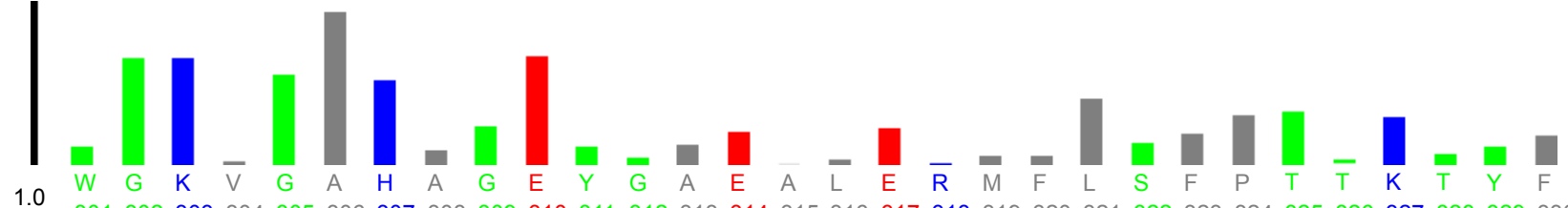

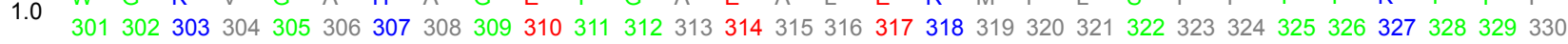

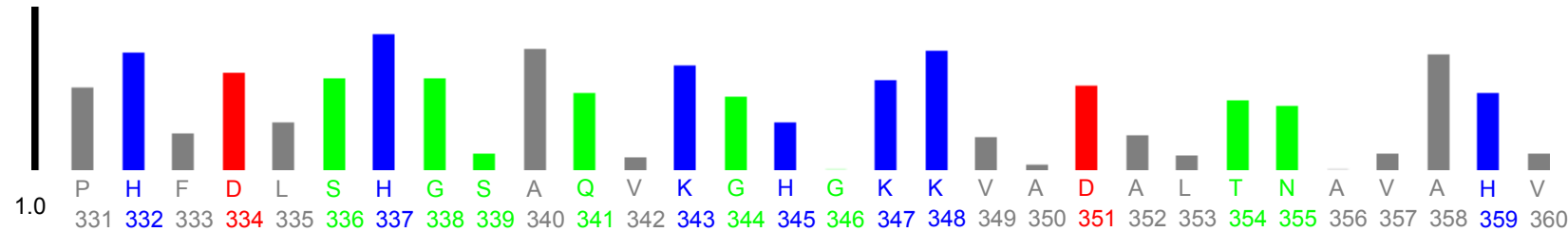

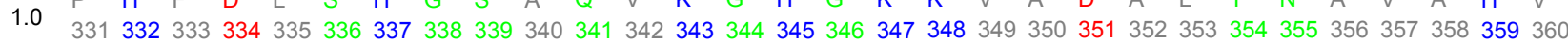
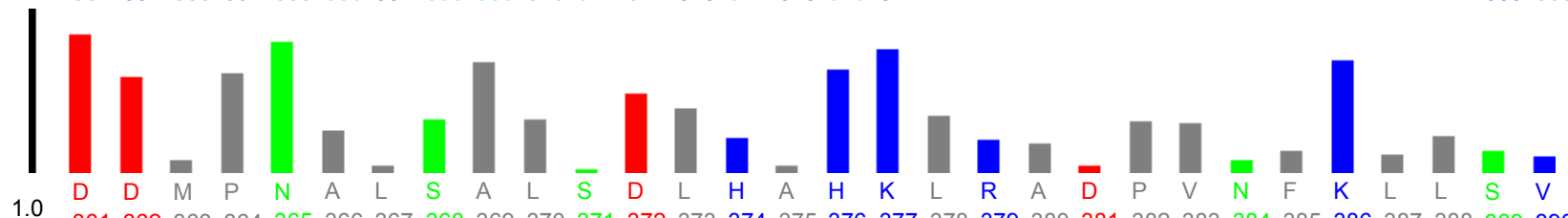

$1.0 \quad 361362363364365366367368369370371372373374375376377378379380381382383384385386387388389390$
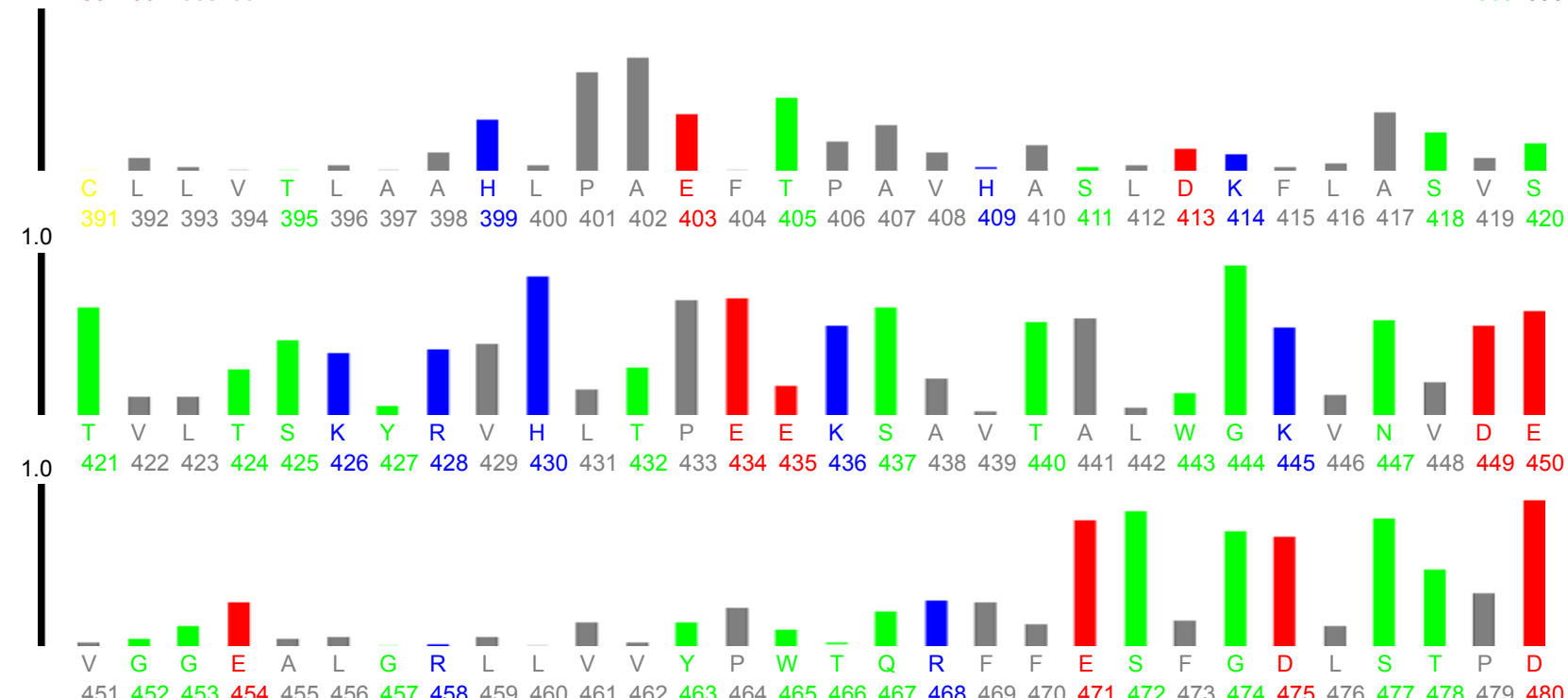

Figure 10 (Continued) 


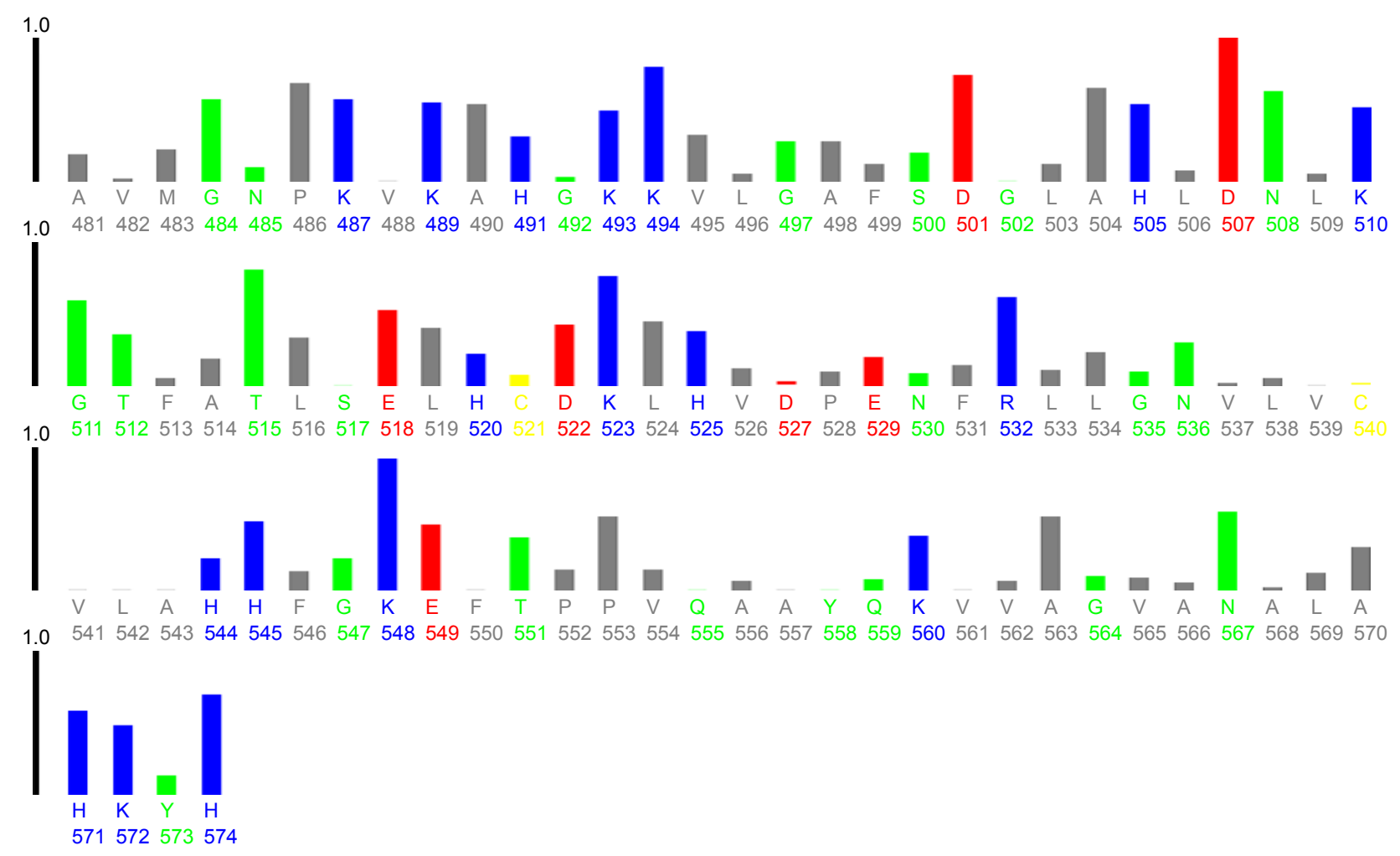

Figure 10 Plot of relative solvent accessibility area of $\mathrm{HHb}$ residues (PDB ID: $2 \mathrm{HHB}$ ) from 0 to I. Color scheme used is: blue, positively charged residues (R, K, and $\mathrm{H}$ ); red, negatively charged residues ( $\mathrm{D}$ and $\mathrm{E}$ ); green, polar uncharged residues (G, N, Y, Q, S, T, and W); yellow, cysteine; gray, hydrophobic residues (all others). This plot was generated by http://www.abren.net/asaview/.

\section{Docking study}

Molecular docking studies have received a great interest in protein-ligand studies. The molecular docking was carried out with both clusters of 1.5 (Figure 11A) and $1 \mathrm{~nm}$ (Figure 12A), respectively. Figure 11B and Figure 12B show the docking results of CNPs with the size of 1.5 and $1 \mathrm{~nm}$ and $\mathrm{HHb}$ (PDB ID: 2H35), respectively. The calculated binding energies were found to be -651.85 and -540.90 E-value for larger and smaller CNP clusters, respectively, revealing a greater binding affinity of $\mathrm{HHb}$ for larger clusters. Graphical tools such as CHIMERA (www.cgl.ucsf.edu/chimera) and PyMOL (http://pymol.sourceforge.net/) were employed to visualize the docked site. The docked poses for CNPs $1.5 \mathrm{~nm} / \mathrm{HHb}$ and CNPs $1 \mathrm{~nm} / \mathrm{HHb}$ are displayed in Figure $11 \mathrm{C}$ and $\mathrm{D}$ and Figure $12 \mathrm{C}$ and D, respectively. The CNPs $(1.5 \mathrm{~nm})$ with interacting residues $(4 \AA)$ are shown in Figure $11 C$ and D. The closest amino acids to larger CNPs are Lys-139, Thr-134, Thr137, Lys-127, Pro-95, Ala-130, Phe-98, Ser-102, and Lys-99 in the $\alpha$-subunit and Trp-37 and Tyr-35 in the $\beta$-subunit.

Tyr-35 and Trp-37 in the $\beta_{2}$-subunit can be renumbered as Tyr-463 and Trp-465, which are in good agreement with the plot of accessible surface area and experimental data.

Therefore, it can be seen that some of interacting residues are aromatic amino acids. Moreover, aromatic residues as well as Ala and Pro residues may provide a hydrophobic environment for the interaction of $\mathrm{HHb}$ with $\mathrm{CNP}$.

The closest amino acids to smaller CNPs are Pro-100, Glu101, Asn-102, Phe-103, Ala-142, Asn-133, Ala-141, Ala-138, Asn-139, and Arg-104 ( $\beta$-subunit; Figure 12C and D).

As evident from the results, data obtained from the larger cluster is more oriented toward experimental data, compared with smaller counterparts. This may be due to the fact that NPs tend to form aggregate species in the colloidal state. Therefore, to validate the theoretical studies, larger NPs should be considered for NP-protein interaction.

Furthermore, CNPs can marginally destabilize the quaternary structure of $\mathrm{HHb}$ as measured by near UV-CD. However, the secondary structure of protein was not altered as detected by far UV-CD. Generally, the interaction of CNPs induces an overall structural readjustment in the $\mathrm{HHb}$, but keeps the $\alpha$-helix scaffold intact. This conformational destabilization may cause regulatory dysfunctions of this type of a CNP-HHb complex. The CNP-induced destabilization of $\mathrm{HHb}$ suggests that, in the absence of other factors that may influence its stability in vivo such as the protein corona, $\mathrm{pH}$, ionic strength, and opsonization process, the probability of CNP-induced conformational changes of $\mathrm{HHb}$ is reduced. Molecular binding of protein onto the NP surface plays a 
A
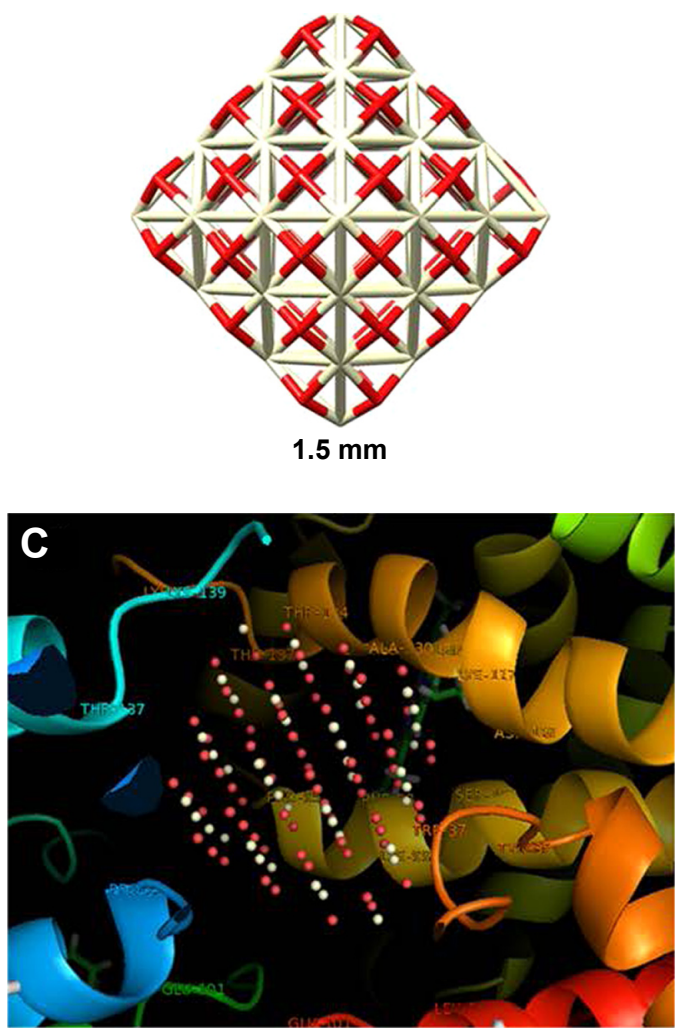

B

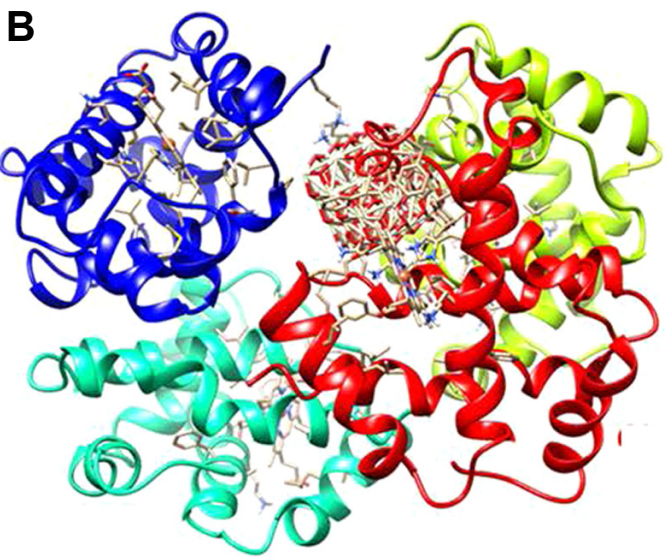

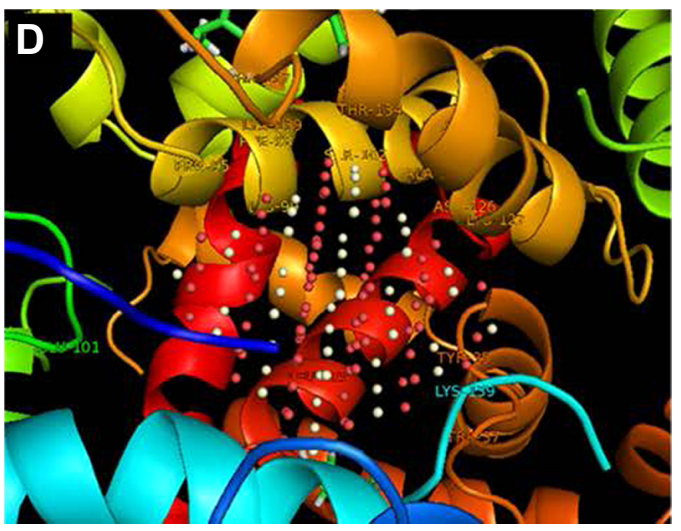

Figure II The CNP cluster with the size of $1.5 \mathrm{~nm}(\mathbf{A})$; docked site of interaction between CNPs and HHb (B); the CNPs with interacting residues (4 A) in two rotational views (C and $\mathbf{D})$.

A
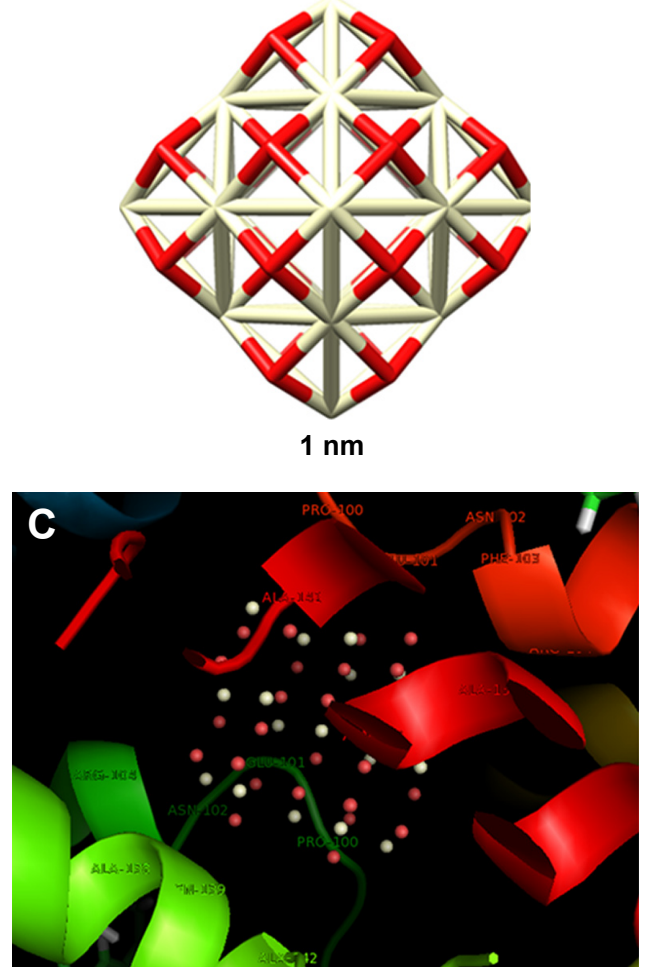

B
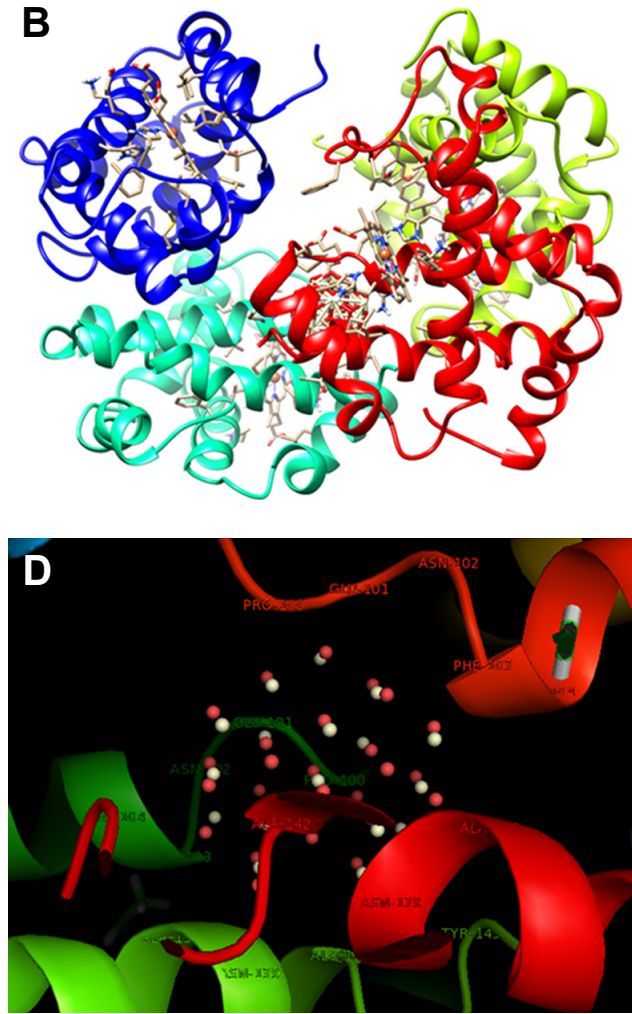

Figure 12 The CNP cluster with the size of I nm (A); docked site of interaction between CNPs and HHb (B); the CNPs with interacting residues (4 Å) in two rotational views $(\mathbf{C}$ and $\mathbf{D})$. 
crucial role in the regulation of protein function in the biological systems. NP-adsorbed proteins change their interactions with other ligands at the molecular level. Indeed, the interaction results in minor or substantial alterations in the structure of the protein, compared with their free counterparts, with immediate interference with their function. The formation of a protein-NP system leads to additional and different thermodynamic and conformational parameters; compared to the free forms of protein and NP partners, both processes - NP binding and NP-induced structural changes are closely correlated. This is more pronounced in the case of multi-subunit proteins with intra- and inter-molecular bonds such that their monomers are denatured, and the system of stability, association, and NP interactions are heavily connected. Thus, NP-binding domains may experience local fluctuation and global unfolding events upon binding to their operator residues.

There were small variations in the displacement of the main aromatic residues as revealed by fluorescence spectroscopy. In addition, a comprehensive analysis by near CD spectra demonstrated minor changes of protein conformation upon interaction with CNPs. These outcomes suggest that the changes in native $\mathrm{HHb}$ mediated by CNPs occur on a local basis, perhaps, mostly in the exposed aromatic residues which would not induce a distinct conformational alteration. The interface would stay constant, as indicated by the minor change in the center of maximum wavelength, dramatically inferring no variation in the displacement of the internal aromatic residues to the solvent.

Exploring the secondary structure of $\mathrm{HHb}$ by far UV-CD indicated a negligible conformational changes in the presence of CNPs. The molecular basis for this event could be the hydrophobic and hydrophilic interactions of the many residues in the pocket site of the native conformation with the CNP surface. Therefore, the CNPs may bind more specifically through oxygen groups on their surface, somehow mimicking the oxygen molecules in the bloodstream.

It has been reported that functionalized carbon nanotubes induced substantial conformational changes in $\mathrm{HHb}$ structure, regardless of single-wall or multi-wall structures. ${ }^{40,41}$ Moreover, it was shown that nanodiamonds can drive secondary structural changes in $\mathrm{HHb}$ structure in a concentration-dependent manner. ${ }^{20}$ However, this study demonstrated that CNPs do not perturb the secondary structure of $\mathrm{Hb}$.

Nerveless, before we can utilize CNP application in biological and medical systems, cellular assays should be conducted to explore the safety of NPs.

\section{MTT assay}

Lymphocytes were used to explore the cytotoxic effect of CNPs. Lymphocytes were incubated with different concentrations of CNPs for $48 \mathrm{~h}$. Cell mortality was evaluated by an MTT assay. It was observed that CNPs suppressed proliferation of lymphocytes (Figure 13). The cell viability was $100 \% \pm 9.11 \%, 97.44 \% \pm 4.12 \%, 87.50 \% \pm 10.76 \%$, $73.06 \% \pm 9.26 \%, 65.39 \% \pm 5.97 \%$, and $59.16 \% \pm 7.08 \%$ after treatment with different concentrations of CNPs from 0 to $1,10,50,100$, and $200 \mu \mathrm{g} / \mathrm{mL}$, respectively. Data displayed in Figure 13 indicated that CNPs $(200 \mu \mathrm{g} / \mathrm{mL})$ induced a remarkable reduction in the cell viability of lymphocytes $(* P<0.05)$ as compared to control. As demonstrated in Figure 13, some cytotoxicity was already determined at the $50 \mu \mathrm{g} / \mathrm{mL}$ concentration of CNPs, whereas a maximal effect was revealed at a concentration of $200 \mu \mathrm{g} / \mathrm{mL}$ in lymphocytes. Based on these data, a CNP concentration of $200 \mu \mathrm{g} /$ $\mathrm{mL}$ was used for the flow cytometry test.

\section{Flow cytometry assay}

Apoptosis, autophagy, and necrosis are known as the leading mechanisms of cell mortality. To calculate the amount of apoptotic and necrotic cells, the cells were incubated with $200 \mu \mathrm{g} / \mathrm{mL}$ of CNPs for $48 \mathrm{~h}$ (Figure 14B) and evaluated by flow cytometry. The results were compared with those of the control group (Figure 14A). It was revealed that CNPs can initiate apoptosis in lymphocytes. The flow cytometry outcome demonstrated that the rate of apoptosis increased from $8 \% \pm 1.33 \%$ to $50.67 \% \pm 7.23 \%$ (*** $P<0.001)$ in cells treated with $200 \mu \mathrm{g} / \mathrm{mL}$ of CNPs after $48 \mathrm{~h}$ (Figure 14C).

Therefore, it may be indicated that the apoptosis pathway is triggered by CNPs in high concentrations.

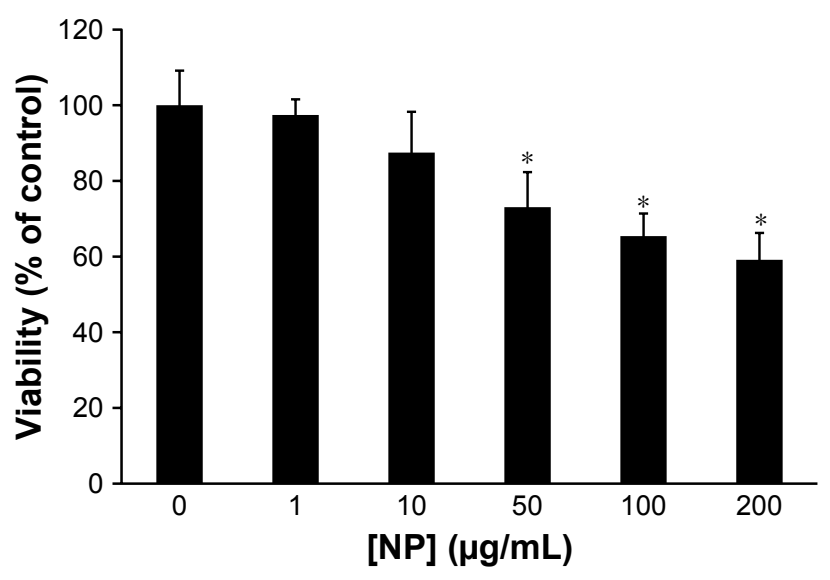

Figure 13 Cytotoxic effect of CNPs with different concentrations on lymphocytes. Data reported as mean $\pm \mathrm{SE}$ of three independent investigations. $* P<0.05$ vs control were considered significant. 

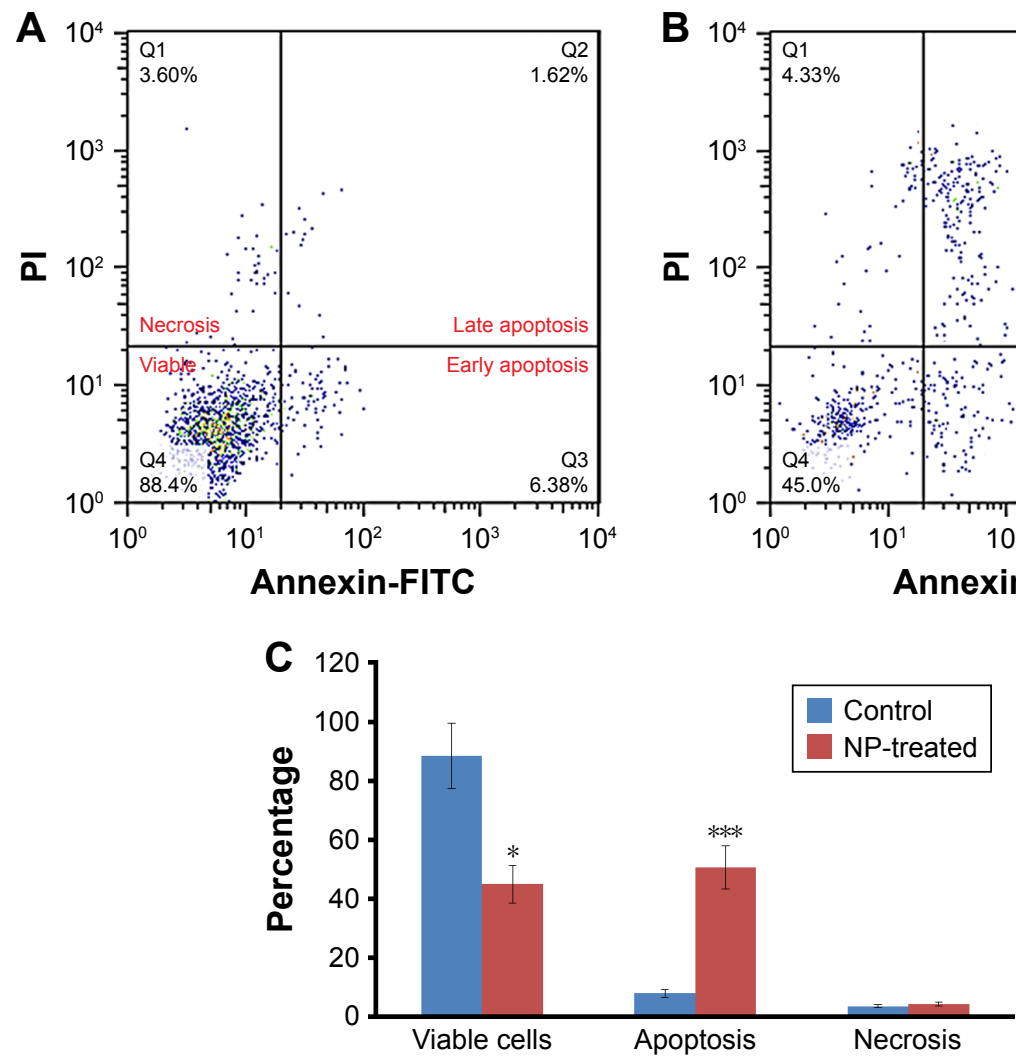

Figure 14 Apoptosis induced by CNPs in lymphocytes. Lymphocytes were incubated with (A) vehicle control and (B) $200 \mu g / \mathrm{mL} \mathrm{CNPs} \mathrm{for} 48$ h. Afterwards, flow cytometric analysis was conducted. (C) Results showing the percentage of viable, apoptotic, and necrotic cells. Data are expressed as mean $\pm S E(n=3)$. $* P<0.05$ and $* * * P<0.00 \mathrm{I}$ vs control group.

Necrosis is initiated by membrane leakage, and apoptosis is mediated through mitochondrial damage. Therefore, it can be suggested that CNPs, after interaction with cells, can mediate cytotoxic effects through mitochondrial pathways.

Consistent with our data, previous reports have indicated that CNPs increase the level of oxidant spices and may trigger apoptosis in human lung epithelial cells. ${ }^{42,43}$ Therefore, CNPs may initiate cytotoxic impacts upon cellular infiltration. It has been well documented that CNPs of different dimensions markedly exhibited adverse impacts on human hepatoma cells and human neutrophils due to oxidative stress. ${ }^{44,45}$ Recently, Khan et al also exhibited the cytotoxic effects of CNPs against a colorectal cancer cell line (HT29) through apoptosis induction. ${ }^{46}$ Forest et al demonstrated that CNPs of various morphologies triggered different mechanisms of cellular toxicity. ${ }^{47}$

Besides these, CNPs have been revealed to protect cells from oxidative stress due to their potential antioxidant features. ${ }^{48-52}$ With these conflicting outcomes, the toxicity of CNPs remains difficult to identify, and distinctive adverse effect targets relevant to human safety needs to be explored. Therefore, it is prudent to develop a systematic investigation

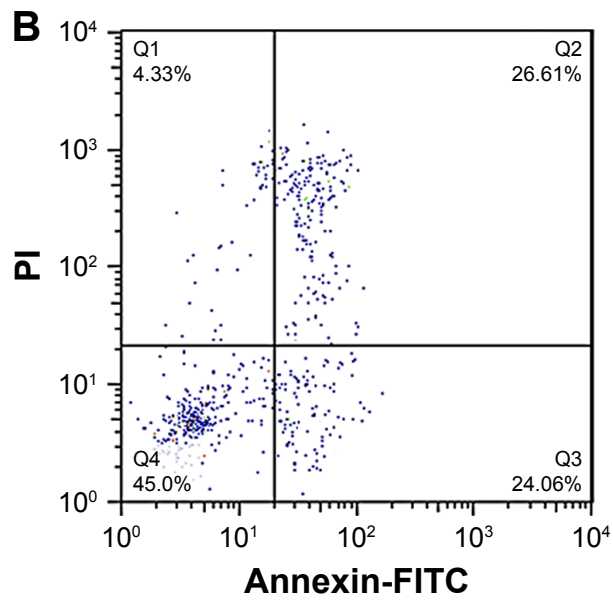

to explore, in detail, the molecular mechanism underlying the toxicity of CNPs.

Together, these findings exhibited that although CNPs did not perturb the conformation of $\mathrm{HHb}$, they can induce some cellular adverse effects at high concentrations that may limit the medicinal and biological application of CNPs.

\section{Future perspectives}

Current uncertainties in nanomaterial assessment in biological systems include NP characterization (size and colloidal stability) and the concentration that correctly delineates and envisages their impacts, and whether they interact with living systems similar to classical xenobiotics. An essential part of investigation quality and standardization with nanomaterials is their characterization. Moreover, an "appropriate" investigation should be conducted in vivo to better explore the fate of NPs upon entry into the body. To better determine the pharmacodynamic and pharmacokinetic parameters of CNPs, a detailed study should be designed to investigate the impact of dimension, morphology, and surface chemistry of CNPs on their distribution and clearance within/from the blood. 
For example, how the HHb-CNP interaction can take place in vivo, because the $\mathrm{Hb}$ is encapsulated within the red blood cells (RBCs) and their membranes are impermeable to the large NPs. However, it may be difficult to correlate the size of NPs with their ability to cross the RBC membrane, because large NPs may damage the membrane, thereby increasing the membrane permeability.

Furthermore, it is not well explored that how CNPs stimulate apoptosis, necrosis, and autophagy in lymphocytes. NP-induced oxidative stress in mitochondria is dependent on the permeability of the cytoplasmic membrane. Therefore, extrinsic and intrinsic cell death pathways should be investigated to determine the signal cascade between mitochondria and the cell surface.

\section{Conclusion}

This research study highlights the reactivity of CNPs with biological systems such as blood components. It was displayed that CNPs affect $\mathrm{HHb}$ structure and lymphocyte viability. Herein, the interaction of CNPs with $\mathrm{HHb}$ and lymphocytes was studied, and it was reported that CNPs induced marginal structural changes of $\mathrm{HHb}$. Moreover, it was shown that CNPs stimulate cytotoxicity against lymphocytes at high concentrations. The interaction of NPs with proteins and cells can provide useful information about NP bio-reactivity. This interaction results in the formation of a complex NP-protein corona. The protein corona may affect protein structure, such as through secondary structural changes, quaternary structural changes, aggregation, heme degradation, and release of metallic ions. The NP-induced cell mortality may affect the overall bio-reactivity of the NPs. Therefore, in depth investigation of such interactions can play a potential role toward generating bio-compatible NPs with defined and controlled surface characteristics in a biological system. The main aim of this study is to provide important knowledge on the NP-blood component interaction.

\section{Acknowledgment}

This research was supported by the Tehran University of Medical Sciences \& Health Services (grant no 96033036151), Tehran, Iran.

\section{Disclosure}

The authors report no conflicts of interest in this work.

\section{References}

1. Abdelhameed AS, Alam P, Khan RH. Binding of Janus kinase inhibitor tofacitinib with human serum albumin: multi-technique approach. J Biomol Struct Dyn. 2016;34(9):2037-2044.
2. Radauer-Preiml I, Andosch A, Hawranek T, et al. Nanoparticle-allergen interactions mediate human allergic responses: protein corona characterization and cellular responses. Part Fibre Toxicol. 2016;13(1):3-10.

3. Iram N, Khan MS, Jolly R, et al. Interaction mode of polycarbazoletitanium dioxide nanocomposite with DNA: molecular docking simulation and in-vitro antimicrobial study. J Photochem Photobiol B. 2015;153:20-32.

4. Nasir Z, Shakir M, Wahab R, et al. Co-precipitation synthesis and characterization of Co doped SnO 2 NPs, HSA interaction via various spectroscopic techniques and their antimicrobial and photocatalytic activities. Int J Biol Macromol. 2017;94(Pt A):554-565.

5. Ye N, Wang Z, Wang S, Peijnenburg WJGM. Toxicity of mixtures of zinc oxide and graphene oxide nanoparticles to aquatic organisms of different trophic level: particles outperform dissolved ions. Nanotoxicology. 2018;12(5):423-438.

6. Wang Z, Zhang F, Wang S, Peijnenburg WJGM. Assessment and prediction of joint algal toxicity of binary mixtures of graphene and ionic liquids. Chemosphere. 2017;185:681-689.

7. Wang Z, Wang S, Peijnenburg WJGM. Prediction of joint algal toxicity of nano-CeO2/nano-TiO2 and florfenicol: independent action surpasses concentration addition. Chemosphere. 2016;156:8-13.

8. Nelson BC, Johnson ME, Walker ML, Riley KR, Sims CM. Antioxidant cerium oxide nanoparticles in biology and medicine. Antioxidants (Basel). 2016;5(2). pii:E15.

9. Bailey ZS, Nilson E, Bates JA, et al. Cerium oxide nanoparticles improve outcome after in vitro and in vivo mild traumatic brain injury. $J$ Neurotrauma. Epub 2016 Nov 2.

10. Zhou D, Fang T, Lu LQ, Yi L. Neuroprotective potential of cerium oxide nanoparticles for focal cerebral ischemic stroke. J Huazhong Univ Sci Technolog Med Sci. 2016;36(4):480-486.

11. Popov AL, Popova NR, Selezneva II, Akkizov AY, Ivanov VK. Cerium oxide nanoparticles stimulate proliferation of primary mouse embryonic fibroblasts in vitro. Mater Sci Eng C Mater Biol Appl. 2016; 68:406-413.

12. Azari A, Shokrzadeh M, Zamani E, Amani N, Shaki F. Cerium oxide nanoparticles protects against acrylamide induced toxicity in HepG2 cells through modulation of oxidative stress. Drug and Chemical Toxicology. 2018:1-6.

13. Pezzini I, Marino A, Del Turco S, et al. Cerium oxide nanoparticles: the regenerative redox machine in bioenergetic imbalance. Nanomedicine (Lond). 2017;12(4):403-416.

14. Naganuma T. Shape design of cerium oxide nanoparticles for enhancement of enzyme mimetic activity in therapeutic applications. Nano Res. 2017;10(1):199-217.

15. Khaksar MR, Rahimifard M, Baeeri M, et al. Protective effects of cerium oxide and yttrium oxide nanoparticles on reduction of oxidative stress induced by sub-acute exposure to diazinon in the rat pancreas. J Trace Elem Med Biol. 2017;41:79-90.

16. Gil D, Rodriguez J, Ward B, Vertegel A, Ivanov V, Reukov V. Antioxidant activity of SOD and catalase conjugated with nanocrystalline ceria. Bioengineering (Basel). 2017;4(1):18-25.

17. Manning LR, Popowicz AM, Padovan JC, Chait BT, Manning JM. Gel filtration of dilute human embryonic hemoglobins reveals basis for their increased oxygen binding. Anal Biochem. 2017;519:38-41.

18. Toma VA, Farcaș AD, Roman I, et al. Comparative in vivo effects of hemoglobin-based oxygen carriers (HBOC) with varying prooxidant and physiological reactivity. PLoS One. 2016;11(4):e0153909.

19. Maurya N, Maurya JK, Kumari M, Khan AB, Dohare R, Patel R. Hydrogen bonding-assisted interaction between amitriptyline hydrochloride and hemoglobin: spectroscopic and molecular dynamics studies. J Biomol Struct Dyn. 2017;35(6):1367-1380.

20. Pishkar L, Taheri S, Makarem S, et al. Studies on the interaction between nanodiamond and human hemoglobin by surface tension measurement and spectroscopy methods. J Biomol Struct Dyn. 2017;35(3):603-615.

21. Jafari Azad V, Kasravi S, Alizadeh Zeinabad H, et al. Probing the conformational changes and peroxidase-like activity of cytochrome c upon interaction with iron nanoparticles. J Biomol Struct Dyn. 2017; 35(12):2565-2577. 
22. Zeinabad HA, Zarrabian A, Saboury AA, Alizadeh AM, Falahati M. Interaction of single and multi wall carbon nanotubes with the biological systems: tau protein and PC12 cells as targets. Sci Rep. 2016;6: 26508.

23. Aghili Z, Taheri S, Zeinabad HA, et al. Investigating the interaction of Fe nanoparticles with lysozyme by biophysical and molecular docking studies. PLoS One. 2016;11(10):e0164878.

24. Zeinabad HA, Kachooei E, Saboury AA, et al. Thermodynamic and conformational changes of protein toward interaction with nanoparticles: a spectroscopic overview. RSC Adv. 2016;6(107):105903-105919.

25. Loschen C, Migani A, Bromley ST, Illas F, Neyman KM. Density functional studies of model cerium oxide nanoparticles. Phys Chem Chem Phys. 2008;10(37):5730-5738.

26. Ritchie DW, Venkatraman V. Ultra-fast FFT protein docking on graphics processors. Bioinformatics. 2010;26(19):2398-2405.

27. Moosavi MA, Sharifi M, Ghafary SM, et al. Photodynamic N-TiO 2 nanoparticle treatment induces controlled Ros-mediated autophagy and terminal differentiation of leukemia cells. Sci Rep. 2016;6:34413.

28. Masui T, Hirai H, Hamada R, et al. Synthesis and characterization of cerium oxide nanoparticles coated with turbostratic boron nitride. J Mater Chem. 2003;13(3):622-627.

29. Caruso ÍP, Barbosa Filho JM, de Araújo AS, de Souza FP, Fossey MA, Cornélio ML. An integrated approach with experimental and computational tools outlining the cooperative binding between 2-phenylchromone and human serum albumin. Food Chem. 2016;196:935-942.

30. Wu Z, Shen L, Han Q, et al. Mechanism and nature of inhibition of trypsin by ligupurpuroside $\mathrm{A}$, a Ku-Ding tea extract, studied by spectroscopic and docking methods. Food Biophys. 2017;12(1):78-87.

31. Rabbani G, Baig MH, Jan AT, et al. Binding of erucic acid with human serum albumin using a spectroscopic and molecular docking study. Int J Biol Macromol. 2017;105(Pt 3):1572-1580.

32. Rahimi-Vaghar R, Divsalar A, Mansouri-Torshizi H. Heme releasing from human hemoglobin upon interaction with a new synthesized complex of 1, 10-phenanthroline-n-butyl dithiocarbamato pd (ii) nitrate. Phys Chem Res. 2013;1(2):185-196.

33. Chen WY, Huang HM, Lin CC, Lin FY, Chan YC. Effect of temperature on hydrophobic interaction between proteins and hydrophobic adsorbents: studies by isothermal titration calorimetry and the van't Hoff equation. Langmuir. 2003;19(22):9395-9403.

34. Perozzo R, Folkers G, Scapozza L. Thermodynamics of protein-ligand interactions: history, presence, and future aspects. J Recept Signal Transduct Res. 2004;24(1-2):1-52.

35. Ajmal MR, Abdelhameed AS, Alam P, Khan RH. Interaction of new kinase inhibitors cabozantinib and tofacitinib with human serum alpha-1 acid glycoprotein. A comprehensive spectroscopic and molecular Docking approach. Spectrochim Acta A Mol Biomol Spectrosc. 2016; 159:199-208.

36. Sabziparvar N, Saeedi Y, Nouri M, et al. Investigating the Interaction of Silicon Dioxide Nanoparticles with Human Hemoglobin and Lymphocyte Cells by Biophysical, Computational, and Cellular Studies. The Journal of Physical Chemistry B. 2018;122(15):4278-4288.

37. Basak P, Debnath T, Banerjee R, Bhattacharyya M. Selective binding of divalent cations toward heme proteins. Front Biol. 2016; 11(1):32-42.
38. Maheshwari N, Khan FH, Mahmood R. Sodium meta-arsenite induced reactive oxygen species in human red blood cells: impaired antioxidant and membrane redox systems, haemoglobin oxidation and morphological changes. Free Radic Res. 2017;51(5):483-497.

39. Chatterjee S, Kumar GS. Binding of fluorescent acridine dyes acridine orange and 9-aminoacridine to hemoglobin: elucidation of their molecular recognition by spectroscopy, calorimetry and molecular modeling techniques. J Photochem Photobiol B. 2016;159:169-178.

40. Wang YQ, Zhang HM, Cao J. Binding of hydroxylated single-walled carbon nanotubes to two hemoproteins, hemoglobin and myoglobin. J Photochem Photobiol B. 2014;141:26-35.

41. Sekar G, Kandiyil ST, Sivakumar A, Mukherjee A, Chandrasekaran N. Binding studies of hydroxylated Multi-Walled Carbon Nanotubes to hemoglobin, gamma globulin and transferrin. JPhotochem Photobiol B. 2015;153:222-232.

42. Lin W, Huang YW, Zhou XD, Ma Y. Toxicity of cerium oxide nanoparticles in human lung cancer cells. Int J Toxicol. 2006;25(6):451-457.

43. Park EJ, Choi J, Park YK, Park K. Oxidative stress induced by cerium oxide nanoparticles in cultured BEAS-2B cells. Toxicology. 2008; 245(1-2):90-100.

44. Cheng G, Guo W, Han L, et al. Cerium oxide nanoparticles induce cytotoxicity in human hepatoma SMMC-7721 cells via oxidative stress and the activation of MAPK signaling pathways. Toxicol In Vitro. 2013;27(3): 1082-1088.

45. Babin K, Antoine F, Goncalves DM, Girard D. TiO2, CeO2 and ZnO nanoparticles and modulation of the degranulation process in human neutrophils. Toxicol Lett. 2013;221(1):57-63.

46. Khan S, Ansari AA, Rolfo C, et al. Evaluation of in vitro cytotoxicity, biocompatibility, and changes in the expression of apoptosis regulatory proteins induced by cerium oxide nanocrystals. Sci Technol Adv Mater. 2017;18(1):364-373.

47. Forest V, Leclerc L, Hochepied JF, Trouvé A, Sarry G, Pourchez J. Impact of cerium oxide nanoparticles shape on their in vitro cellular toxicity. Toxicol In Vitro. 2017;38:136-141

48. Soren S, Jena SR, Samanta L, Parhi P. Antioxidant potential and toxicity study of the cerium oxide nanoparticles synthesized by microwavemediated synthesis. Appl Biochem Biotechnol. 2015;177(1):148-161.

49. Eriksson P, Tal AA, Skallberg A, et al Cerium oxide nanoparticles with antioxidant capabilities and gadolinium integration for MRI contrast enhancement. Scientific Reports. 2018;8(1):6999.

50. Rubio L, Annangi B, Vila L, Hernández A, Marcos R. Antioxidant and anti-genotoxic properties of cerium oxide nanoparticles in a pulmonarylike cell system. Arch Toxicol. 2016;90(2):269-278.

51. Xue Y, Balmuri SR, Patel A, Sant V, Sant S. Synthesis, physicochemical characterization, and antioxidant effect of PEGylated cerium oxide nanoparticles. Drug Deliv Transl Res. 2018;8(2):357-367.

52. Sadhu A, Ghosh I, Moriyasu Y, Mukherjee A, Bandyopadhyay M. Role of cerium oxide nanoparticle-induced autophagy as a safeguard to exogenous H2O2-mediated DNA damage in tobacco BY-2 cells. Mutagenesis. 2018;33(2):161-177.
International Journal of Nanomedicine

\section{Publish your work in this journal}

The International Journal of Nanomedicine is an international, peerreviewed journal focusing on the application of nanotechnology in diagnostics, therapeutics, and drug delivery systems throughout the biomedical field. This journal is indexed on PubMed Central, MedLine, CAS, SciSearch ${ }^{\circledR}$, Current Contents ${ } /$ Clinical Medicine,

\section{Dovepress}

Journal Citation Reports/Science Edition, EMBase, Scopus and the Elsevier Bibliographic databases. The manuscript management system is completely online and includes a very quick and fair peer-review system, which is all easy to use. Visit http://www.dovepress.com/ testimonials.php to read real quotes from published authors. 